\title{
Machinability analysis of dry and liquid nitrogen-based cryogenic cutting of Inconel 718: experimental and FE analysis
}

\author{
Salman Pervaiz ${ }^{1} \cdot$ Sathish Kannan ${ }^{2} \cdot$ Saqib Anwar $^{3} \cdot$ Dehong Huo $^{4}$ D
}

Received: 6 April 2021 / Accepted: 1 October 2021 / Published online: 18 October 2021

(c) The Author(s) 2021

\begin{abstract}
Inconel 718 is famous for its applications in the aerospace industry due to its inherent properties of corrosion resistance, wear resistance, high creep strength, and high hot hardness. Despite the favorable properties, it has poor machinability due to low thermal conductivity and high hot hardness. To limit the influence of high cutting temperature in the cutting zone, application of cutting flood is recommended during the cutting operation. Cryogenic cooling is the recommended method when machining Inconel 718. However, there is very limited literature available when it comes to the numerical finite element modeling of the process. This current study is focused on the machinability analysis of Inconel 718 using numerical approach with experimental validations. Dry and cryogenic cooling methods were compared in terms of associated parameters such as chip compression ratio, shear angle, contact length, cutting forces, and energy consumption for the primary and secondary deformation zones. In addition, parameters related to chip morphology were also investigated under both lubrication methods. Chip formation in cryogenic machining was well captured by the finite element assisted model and found in good agreement with the experimental chip morphology. Both experimental and numerical observations revealed comparatively less chip compression ratio in the cryogenic cooling with larger value of shear plane angle. This results in the smaller tool-chip contact length and better comparative lubrication.
\end{abstract}

Keywords Cryogenic $\cdot$ Cutting process $\cdot$ Lubrication strategies $\cdot$ Inconel 718

\section{Introduction}

The group of superalloys formed by combining austenitic nickel and chromium is termed as Inconel. Inconel group generally exhibits high strength against creep at elevated temperatures, high hardness, corrosion resistance, and wear resistance. These properties make them suitable candidate for high temperature applications such as aerospace industry.

Dehong Huo

dehong.huo@ncl.ac.uk

1 Department of Mechanical and Industrial Engineering, Rochester Institute of Technology - Dubai Campus, P.O. Box 341055, Dubai, United Arab Emirates

2 Department of Mechanical Engineering, School of Engineering, American University of Sharjah, P.O. Box 26666, Sharjah, United Arab Emirates

3 Industrial Engineering Department, College of Engineering, King Saud University, Riyadh, Saudi Arabia

4 Mechanical Engineering, School of Engineering, Newcastle University, Newcastle upon Tyne NE1 7RU, UK
Inconel 718 is widely used in different structural parts of jet engine such as cases, turbines, and exhaust parts. Inconel 718 also provides good resistance against the exposure of chlorides, stress cracking, and stress corrosion. These properties make them suitable for oil and gas sector as well. Inconel 718 is termed as difficult to machine material due to the very high strength, high hot hardness, and low thermal conductivity. In order to improve heat dissipation during the cutting process, the utilization of cutting fluid is recommended. Application of cutting fluid improves over all machining process by improving tool life and surface integrity and reducing associated costs. Utilization of conventional cutting fluids is also being questioned due to their negative environmental impact. Researchers are exploring the potential of different green cooling/lubrication strategies to machine Inconel 718. Cryogenic cooling termed as one of green solutions for machining Inconel 718.

It is evidenced from several sources found in the metal cutting literature that application of cryogenic cooling at the tool-chip cutting interface results in the improvement of hardness and strength of the cutting tool material, reduces 
the toughness of the materials making it more brittle, and reduces the chemical reactivity/built-up-edge formation at the cutting interface and lowering the coefficient of friction. Hong and Zhao [1] investigated the performance of cryogenic cooling during the cutting process; they figured out that workpiece's ductility and toughness are reduced due to the exposure of cryogenic fluid. Reduction in ductility and toughness improves machinability. The study also pointed out at the efficient cooling at the cutting interface that reduces the possibility of built-up-edge (BUE) formation. Reduction in ductility of the workpiece material improves that chip breakability and chip up curling can be facilitated to lower the tool chip contact length. Cryogenic fluid's temperature also helps to maintain the strength of cutting tool material resulting in lower tool wear. However, the performance of cryogenic cooling is highly linked with the tool-workpiece material pair [2]. Nouzil et al. [3] numerically investigated the influence of jet radius, jet location, and cutting speed when machining Inconel 718. The work has studied shear angle and chip compression ratio to understand the influence of metal cutting process physics. The study revealed that change in jet location influences on the shear angle and it can increase the shear angle that can decrease the shear area and hence reduce the cutting forces and cutting power. De Bartolomeis et al. [4] provided a complete section about the cryogenic machining of Inconel 718 in the review article. The study also provided a brief comparison with conventional flood cooling as a reference. The study concluded that cryogenic cooling provides a superior surface roughness, surface integrity, environment friendliness, and evaporation of dangerous particles etc. over conventional flood cooling method.

Shah et al. [5] conducted drilling study on Inconel 718 under the cryogenic cooling, and life cycle assessment (LCA) was performed to draw meaningful results towards sustainability. LCA revealed $19 \%$ power consumption in $\mathrm{CO} 2$ cooling as compared to the LN2 cooling. Chaabani et al. [6] investigated machining performance of Inconel 718 under both $\mathrm{CO} 2$ and LN2 cooling approaches. The study revealed that residual stress profile was improved in both methods when compared against the conventional flood cooling method. Liu et al. [7] provided a detailed review about the existing studies and efforts towards the modeling of Inconel 718 machining. The study pointed out that the chip generation in Inconel 718 machining is very complicate to model due to interfacial friction, plastic deformation, work hardening, and heat generation. Pereira et al. [8] performed milling experiments on Inconel 718 using CO2-based cryogenic method. Shokrani et al. [9] studied a hybrid cooling setup that coupled cryogenic cooling and MQL in the milling process of Inconel 718. Liquid nitrogen (LN2) and rapeseed oil were used for cryogenic and MQL setup, respectively. A 77\% increase in tool life was observed with the hybrid setup when compared to flood cooling. Chip formation is also an important factor that describes the machinability of certain tool-workpiece material pair. At higher cutting speeds, higher level of cutting temperature is produced at the cutting interface and as a result chip formation can be continuous in nature posing problems during the machining operation. The lower surface of the chip that rubs against the rake face of the tool has elongated grains after recrystallization. It has been observed that smaller chips cannot be produced due to the presence of longer grains on the lower surface of the chip [10]. Due to the reduction in the longer grain size on the lower surface of the chip, chip tends to bend and curl in a way that increases chip breakability. Moreover, material of chip becomes brittle that facilitates chip breaking [11].

It is also observed that at higher cutting speed levels, higher cutting temperature can initiate thermal softening phenomenon for the ductile material; as a result, the workpiece material tends to weld with the cutting tool material resulting a built-up-edge (BUE). This built-up-edge (BUE) can vary the machining performance because this BUE keeps forming and breaking during the machining process. BUE also changes the rake angle of the cutting tool due to the deposition of material; this new rake angle is known as effective rake angle. The breaking and formation of BUE tend to generate vibration in the machining process and result in very poor surface finish. Exposure of low temperature cryogenic coolant can change the hardness, stiffness, and toughness of the cutting tool possibly resulting in the reduction of coefficient of friction $(\mathrm{CoF})$. Figure 1 represents the schematic illustration of the machining performance under cryogenic cooling method. Bagherzadeh et al. [12] studied the effect of cryogenic $\mathrm{CO} 2+\mathrm{MQL}$ technique and a special CMQL technique on turning operation of Inconel 718. Hybrid cooling strategy of $\mathrm{CO} 2+\mathrm{MQL}$ yielded no improvement in tool life compared to cryogenic cooling. CMQL technique increased the tool life by $30 \%$ compared to $\mathrm{CO} 2$ cooling. Hybrid cooling strategy of $\mathrm{CO} 2+\mathrm{MQL}$ outlined by Periera et al. [13] performed better than dry, MQL and cryogenic cooling strategies. Tool life equivalent to over $90 \%$ of wet machining was achieved with hybrid cooling.

There are also some efforts by researchers to model the finite element simulations related to the cryogenic machining. Stampfer et al. [14] developed a thermomechanical coupled finite element model for Ti6Al4V machining. The study developed model for internal and external cooling of LN2, and heat dissipation was studied. The study also provided optimal distance of $1.5 \mathrm{~mm}$ between channel edge and flank face. Umbrello et al. [15] developed a cryogenic machining model for AZ31B magnesium alloy. The model was focused towards the residual stresses, and study revealed that sequential cutting has major influence towards the residual stress formation in machined samples. Rotella and Umbrella in another study compared dry and cryogenic cutting of aluminum alloy using finite element model. The study 
Fig. 1 Schematic illustration of the cryogenic machining mechanisms

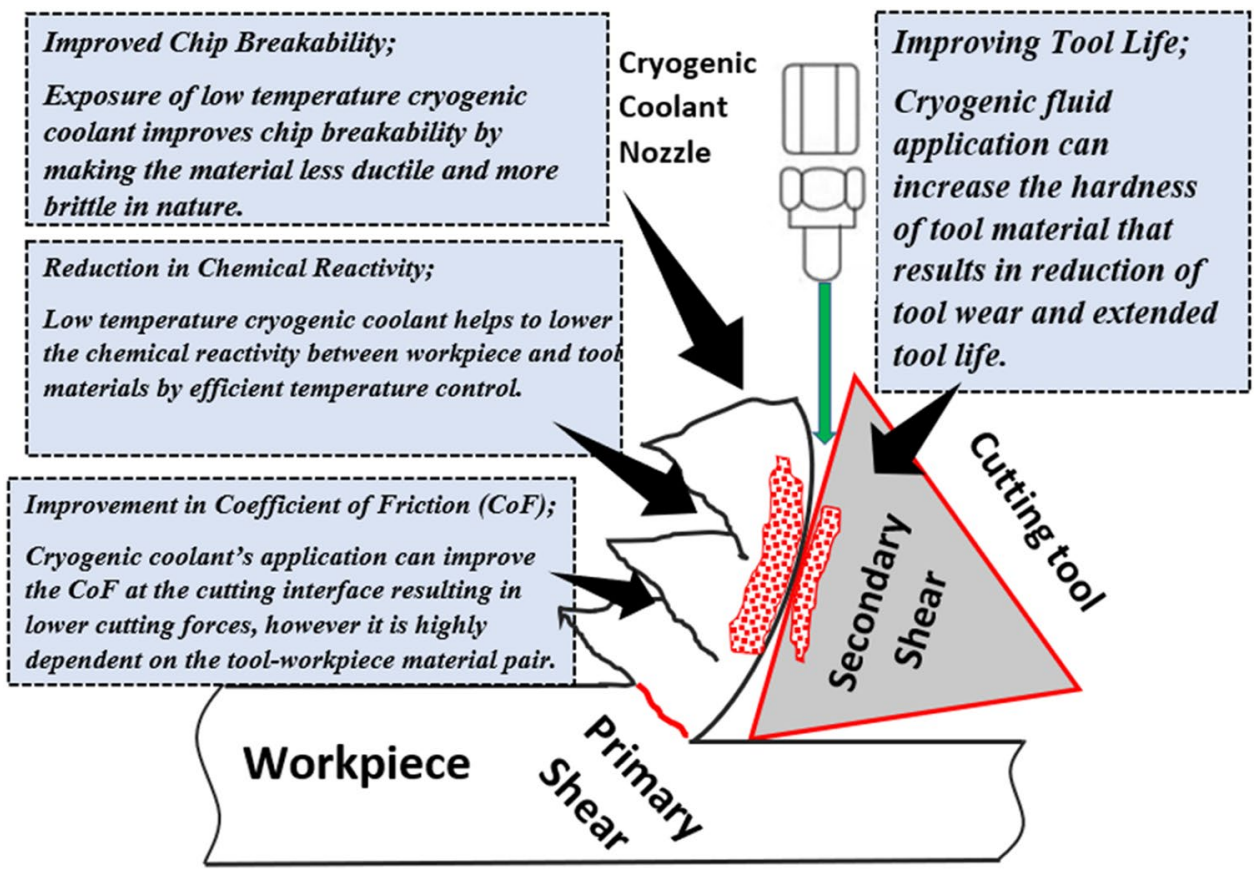

incorporated Zener-Hollomon parameter and Hall-Petch equation to get the behavior of grain size and hardness.

Ayed et al. [16] conducted a cryogenic assisted machining based study using Ti6Al4V and studied the influence of coolant jet characteristics such as pressure and flow rate. The study revealed that best performance was obtained at higher pressure and flow rate. Khanna et al. [17] pointed out another research gap in the area of cryogenic machining that is linked with the parameters involved in the design of cryogenic delivery setups. The study concluded that further research work is needed towards the impact assessment of design parameters of delivery system. More knowledge in that area can help in the industrialization of this cooling method when machining high-performance materials. A major challenge associated with the design is to achieve higher pressures. The major cryogenic delivery techniques involved are based on natural expansion of cryogens available at higher pressure and heating based electrical resistance to achieve higher pressure.

Literature review of the state-of-the-art revealed that there is a very limited finite element based numerical works available for the cryogenic machining of Inconel 718. De Bartolomeis et al. [18] in their review paper pointed out lack of predictive models available when it comes to the machining of Inconel 718. Deshpande et al. [19] also identified the research gap that there is a need to have more reliable predictive models. In this study, dry and cryogenic machining environments are numerically modelled in the AdvantEdge, specialized machining software, with experimental validations. The simulated data is used to provide a deeper analysis of (i) primary shear deformation zone by calculating the chip compression ratio, shear angle, and contact length; (ii) specific cutting energy (SCE); and (iii) chip morphology such as segmentation, valleys, and peaks for plastic deformation.

\section{Experimental design}

\subsection{Material preparation, cutting tool, and machine tool}

The workpiece material was selected to be Inconel 718 for this study. Raw material was present in the cylindrical shape with $50 \mathrm{~mm}$ as diameter and $500 \mathrm{~mm}$ length. To execute the orthogonal cutting experiments, several cylindrical discs were prepared out of the raw material bar as shown in Fig. 2. The study was executed to focus on the continuous cutting under turning experimentation (Fig. 3) (Table 1).

To perform the orthogonal machining experiments, PVD TiAlN coated triangular shaped cutting inserts (TPGN 220,408, Grade: KCU 10, manufactured by Kennametal) were employed. KCU 10 grade is composed of advanced multilayer PVD coating over a very deformation-resistant unalloyed carbide substrate. The cutting inserts were mounted on CTCPN2520M22 tool holder.

Machining experimentation was conducted using a $\mathrm{CNC}$ turning center. CNC turning center was of model Excel BNC-21437 and controller of the machine was Fagor $800 \mathrm{~T}$. The overall machining setup for experimentation has been shown in Fig. 4. As per the recommendations of the cutting tool manufacturer, design of experiment was constructed using recommended cutting parameters as reported 
Fig. 2 Workpiece preparation for orthogonal machining setup
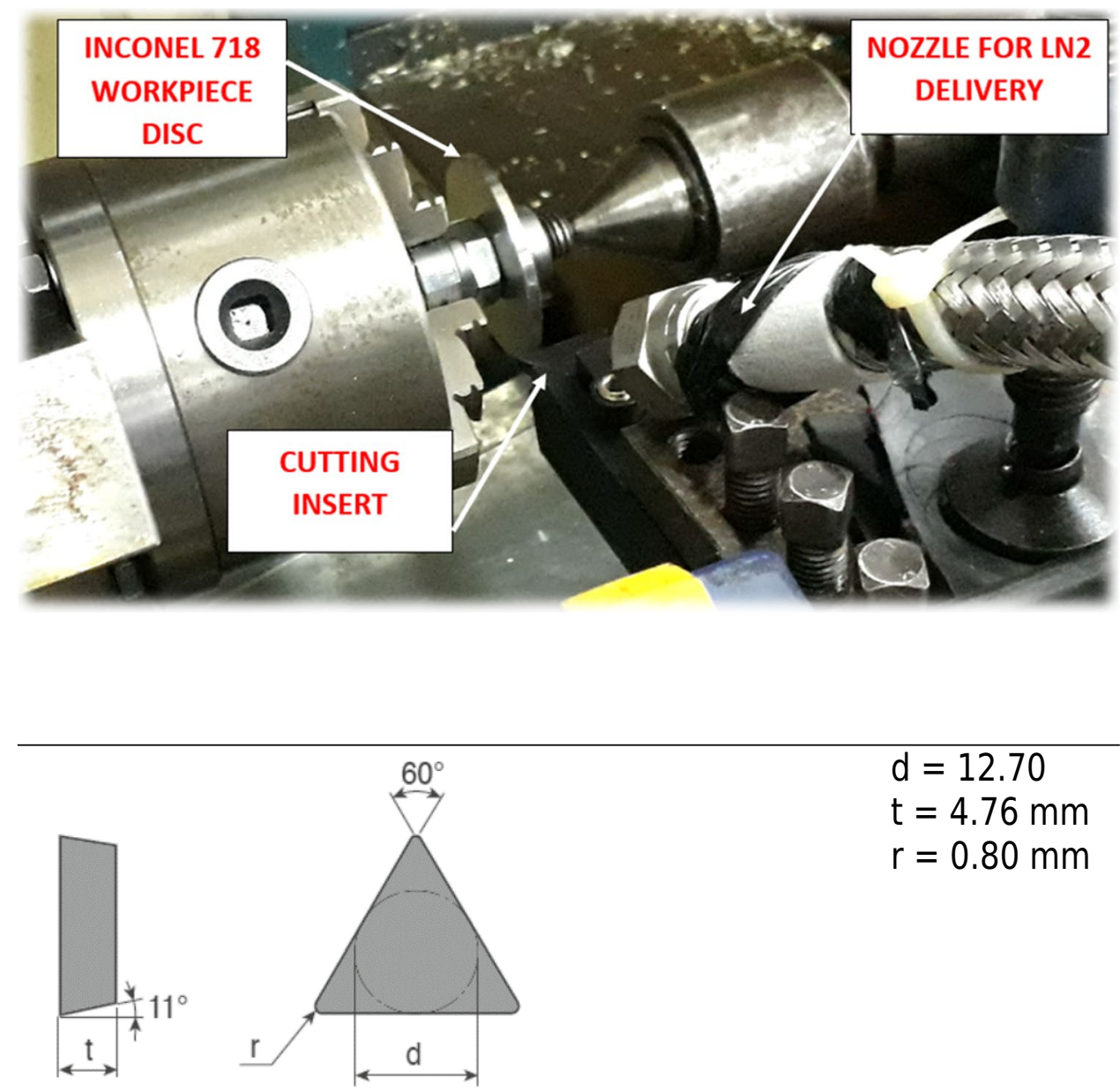

$\mathrm{d}=12.70$
$\mathrm{t}=4.76 \mathrm{~mm}$
$\mathrm{r}=0.80 \mathrm{~mm}$

(a)
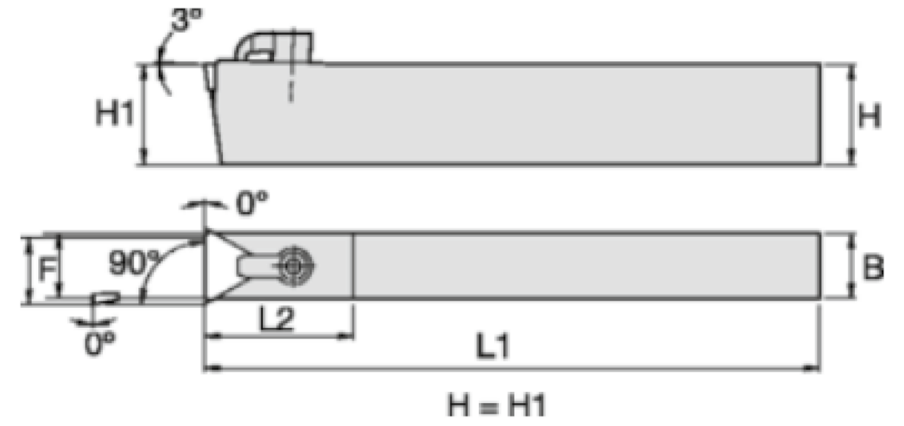

$$
\begin{aligned}
& \mathrm{H}=25 \mathrm{~mm} \\
& \mathrm{~B}=20 \mathrm{~mm} \\
& \mathrm{~F}=20.2 \mathrm{~mm} \\
& \mathrm{~L} 1=150 \\
& \mathrm{~mm} \\
& \mathrm{~L} 2=41 \mathrm{~mm}
\end{aligned}
$$

(b)
Table 1 Mechanical properties of Inconel 718 at room temperature

\begin{tabular}{ll}
\hline Type of property & Value \\
\hline Tensile strength & $1375 \mathrm{MPa}$ \\
Yield strength & $1100 \mathrm{MPa}$ \\
Elongation & $25 \%$ \\
Poisson's ratio & 0.3 \\
Modulus of elasticity & $200 \mathrm{GPa}$ \\
Density & $8190 \mathrm{~kg} / \mathrm{m}^{3}$ \\
\hline
\end{tabular}

in Table 2. Appendix Table 5 has informed about the test conditions.

Keeping in view that continuous cutting mode is more aggressive in machining, turning experiments were conducted under cryogenic machining environment. To have proper comparison, dry and flood cutting experiments were also performed. Machinability was experimentally investigated using the output responses in the form of cutting forces, power, and chip morphology. Liquid nitrogen was delivered from the direction of 
Fig. 4 Overall experimental setup with the output responses

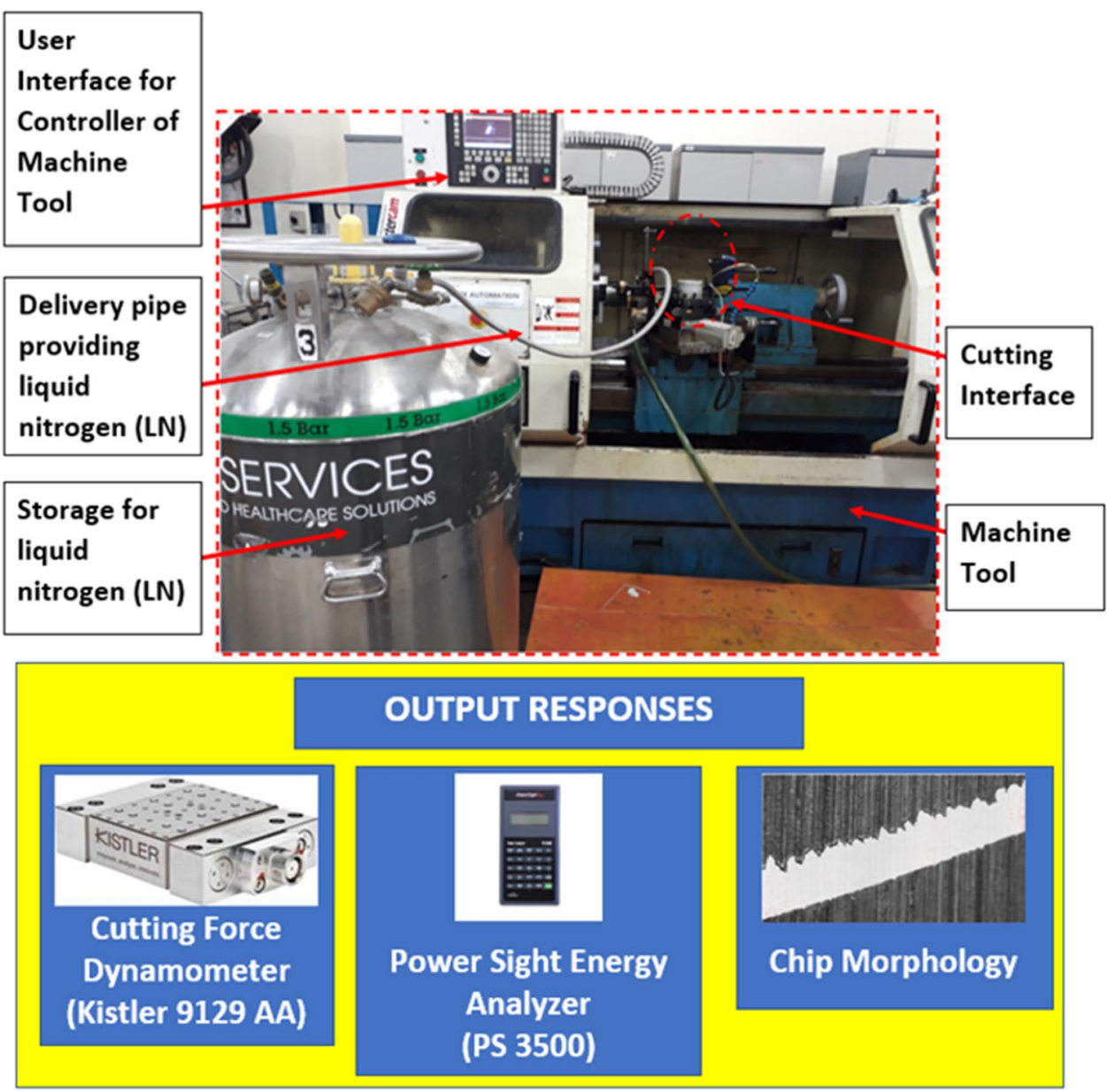

the tool rake face with the flow rate of approximately $0.5 \mathrm{~kg} /$ min mass under 1.5 bar pressure. The outer nozzle diameter was $3 \mathrm{~mm}$, and it was directed in the cutting zone at an ejecting angle of $45^{\circ}$. The ejecting method was only rake face in this work. The constant distance of approximately $12 \mathrm{~mm}$ was kept between the nozzle and the cutting tool. A KISTLER ${ }^{\text {TM }}$ 9129AA three-channel dynamometer was used along with a multichannel charge amplifier type 5080 to measure the machining forces. Appendix Table 6 has specification of the dynamometer. KISTLER ${ }^{\text {TM }}$ Dynoware software package was used to process the output signal from charge amplifier. The measurement was made with an acquisition rate of $10,000 \mathrm{~Hz}$. The chip morphology was investigated and observed by using optical microscope.

\section{2D numerical methodology for dry and cryogenic cutting}

A 2D finite element numerical model was developed using Third wave System (TWS) special finite element solver named as AdvantEdge. AdvantEdge can simulate the 2D cutting process with chip formation. The solver works on explicit Lagrangian assisted code to run coupled thermo-mechanical transient analysis. Chip formation is the result of remeshing and adaptive meshing. The cutting tool was modelled using the carbide as tool material and edge radius of $0.040 \mathrm{~mm}$. Rake angle was kept at $0^{\circ}$ in all simulations. Lagrangian formulation of weak form of momentum is stated in Eq. 1. The formulation was established using the principle of virtual work [20].

$\int_{B_{o}} P_{n+1}: \nabla_{o} \eta d V_{o}-\int_{B_{o}}\left(f_{n+1}-\rho_{0} \alpha_{n+1}\right) \cdot \eta d V_{0}-\int_{\partial B_{o_{r}}} \bar{t}_{n+1} \cdot \eta d S_{o}=0$

In Eq. $1, P n+1$ shows first Piola-Kirchoff; $n+1$ depicts time in $\mathrm{tn}+1$ : $\mathrm{tn}+1$ is body traction, $\mathrm{fn}+1$ is body forces, and an +1 is an acceleration; $\nabla$ o depicts deformation gradient; $\eta$ depicts admissible virtual displacement; and Bo is reference configuration with the density of po. Once spatial discretization is established, then the matrix form is employed as shown in Eq. 2 [20].

$M \alpha_{n+1}+R_{n+1}^{i n t}=R_{n+1}^{e x t}$

where $\mathrm{M}$ describes the mass matrix, an +1 depicts acceleration vector, external force vector is represented by $R_{n+1}^{\text {ext }}$, and internal force vector is depicted by $R_{n+1}^{\text {int }}$. Time integration is accomplished by means of central difference scheme 
Table 2 Machining/lubrication parameters and their levels

\begin{tabular}{llll}
\hline Parameters & Level 1 & Level 2 & Level 3 \\
\hline $\begin{array}{l}\text { Cooling/lubrica- } \\
\text { tion method }\end{array}$ & Dry & Cryogenic & - \\
$\begin{array}{c}\text { Cutting speed, } v_{\mathrm{c}} \\
(\mathrm{m} / \mathrm{min})\end{array}$ & 60 & 90 & 120 \\
$\begin{array}{l}\text { Feed, } f(\mathrm{~mm} / \\
\text { rev })\end{array}$ & 0.05 & 0.1 & 0.15 \\
$\begin{array}{l}\text { Depth of cut, } \\
\text { DoC (mm) }\end{array}$ & 3 & - & - \\
$\begin{array}{c}\text { Cutting insert } \\
\text { Kennametal }\end{array}$ & TiAlN 1 & & \\
\hline
\end{tabular}

as represented in Eqs. 3, 4, and 5, where displacement and velocity are represented in Eqs. 3 and 5 respectively [20].

$$
\begin{aligned}
& d_{n+1}=d_{n}+\Delta t V_{n}+\frac{1}{2} \Delta t^{2} a_{n} \\
& a_{n+1}=M^{-1}\left(R_{n+1}^{\text {ext }}-R_{n+1}^{\text {int }}\right) \\
& V_{n+1}=V_{n}+\Delta t\left(a_{n+1}+a_{n}\right)
\end{aligned}
$$

The weak form of configuration $\mathrm{B} t$ is shown in Eq. 6 to represent the heat transfer.

$$
\int_{B_{t}} \rho c \dot{T} \eta d V+\int_{\partial B_{t q}} h \eta d S=\int_{B_{t}} q \cdot \nabla \eta d V+\int_{B_{t}} s \eta d V
$$

where $\mathrm{T}$ shows temperature field, $\mathrm{q}$ shows heat flux, and $\mathrm{h}$ is frictional heat (tool-chip interface). The explicit time integration is utilized for thermal case as shown in Eq. 7. In Eq. 7, temperature vector is $\mathrm{T}$, thermal conductivity is $\mathrm{K}$, heat capacity is $\mathrm{C}$, and heat source vector is represented by $\mathrm{Q}$.

$T_{n+1}=T_{n}+\Delta t C^{-1}\left(Q_{n}-K_{n} T_{n}\right)$

There are different possibilities in the software package to model the constitutive behavior of the workpiece material. The workpiece material (Inconel 718) in this study was modelled using advanced representation of power law. This advanced power law has capability to incorporate damage law along with temperature-dependent thermal conductivity and heat capacity [21]. Workpiece was meshed with minimum element size of 0.02 and maximum size of 0.1 for a total number of 24,000 nodes. A high density of mesh was defined at the cutting edge and adaptive remeshing enabled to avoid elemental distortions beyond certain tolerance. When elemental distortions exceed the decided tolerance, adaptive remeshing is triggered automatically. The meshing is continuously monitored, and elemental distortion is fixed by continuous refinement and improvement [22]. The mesh refinement factor and coarsening factors were set as 2 and 6 respectively.

The advanced power law utilized in the current work is represented in Eq. 8 [21]. The power law incorporates strain hardening function as $\mathrm{g}\left(\varepsilon^{p}\right)$ and thermal softening function as $\theta(T)$, and rate sensitivity function is given by $\tau(\dot{\varepsilon})$.

$\sigma\left(\varepsilon^{p}, T, \dot{\varepsilon}\right)=g\left(\varepsilon^{p}\right) \theta(T) \tau(\dot{\varepsilon})$

The modeling of strain hardening function is represented by Eq. 9 as shown below. In order to utilize the function of strain hardening, stress strain data of a workpiece material can be examined and curve fitting. Strain rate sensitivity function is modelled Eq. 10 [21]. To form precise chip shape and cutting force behavior, it is important that model is capable to incorporate thermal softening behavior as well. Thermal softening function was introduced in the power law with fifth-order polynomial equation as described in Eq. 11 [21].

$g\left(\varepsilon^{p}\right)=\sigma o\left[1+\frac{\varepsilon^{p}}{\varepsilon^{p} o}\right]^{\frac{1}{n}}$ if $\varepsilon^{p}<\varepsilon_{c u t}^{p}$

In the above Eq. $9, \sigma o$ is the initial yield stress, $\varepsilon^{p}$ is plastic strain, $\varepsilon_{o}^{p}$ is reference plastic strain, and $1 / n$ is referred as the strain hardening power. The values of initial yield stress can be obtained by the data of stress strain from uniaxial compression or tensile test of workpiece material. The values of $\varepsilon_{o}^{p}$ and $n$ are obtained by curve fitting the stress strain data (Fig. 5).

The AdvantEdge software manual and literature [24, 25] were consulted to obtain all the required parameters for the Inconel 718 material model. The strain hardening component of the workpiece material model is modelled by the fitting of stress-strain curve for Inconel 718 as shown in Fig. 6. The experimental data to curve fitting for strain hardening, strain rate components, and thermal softening are obtained from the literature $[23,26]$.

$\tau(\dot{\varepsilon})=\sigma o\left[1+\frac{\dot{\varepsilon}}{\dot{\varepsilon} o}\right]^{\frac{1}{m 1}}$

In Eq. 3, the function represents the flow stress behavior at higher strain rates. In this equation, $\dot{\varepsilon}$ is the plastic strain rate and $\dot{\varepsilon}_{o}$ is the reference plastic strain rate and $m_{l}$ is the strain rate sensitivity.

$$
\begin{aligned}
& \theta(T)=c_{0}+c_{1} T^{1}+c_{2} T^{2}+c_{3} T^{3}+c_{4} T^{4}+c_{5} T^{5} \text { if } T<T_{\text {cut }} \\
& \theta(T)=\theta\left(T_{\text {cut }}\right)\left(1-\frac{T-T_{\text {cut }}}{T_{m}-T_{\text {cut }}}\right) \text { if } T>T_{\text {cut }}
\end{aligned}
$$

In Eqs. 11 and 12, thermal softening function is represented. Thermal softening function is composed of 5 th-order polynomial with $\mathrm{C} 1-\mathrm{C} 5$ constants. These constants $\mathrm{C} 1-\mathrm{C} 5$ 
are curve fitted by the compression test data at elevated temperatures. Where $T$ is the temperature during the test, $T_{m}$ is the melting temperature and $\mathrm{T}_{\text {cut }}$ is the cut-off temperature. Figure $6 \mathrm{a}$ and $\mathrm{b}$ show the strain hardening and thermal softening behaviors obtained using the experimental data in Fig. 5.

AdvantEdge uses the classical sliding friction concept to model the friction at tool chip contact. The theoretical concept is based on the relation that frictional sliding force is directly proportional to the normal load. The ratio of these forces is attributed as coefficient of friction $(\mu)$ and taken as a constant value along the tool chip contact length as in Eq. 13. The value of friction coefficient was implemented using the calculations using Eq. 14 [27].

$T=\mu \sigma_{n}$

$\mu=\frac{F_{c} \tan \alpha+F_{t}}{F_{c}-F_{t} \tan \alpha}$

Damage in the workpiece material is also very important to produce chip shape. Advantage can simulate damage in the workpiece material by using a damage function D. The damage function $D$ is shown in Eq. 15. The fracture strain can be represented using temperature-dependent model as shown in Eq. 16 [21]. In the current study, parameters were curve fitted to polynomial function using the Johnson Cook (JC) damage model [28, 29]. Table 3 shows the constants used in the current study. The variation of thermal conductivity and specific heat capacity with temperature for Inconel 718 is obtained from [30] as shown in Fig. 7. Damage starts in an element when the value of the "dimensionless damage function" of that element reaches 1 , where $\Delta \varepsilon_{i}^{p}$ is the instantaneous increment of strain in the element, and $\varepsilon_{f_{i}}^{p}$ is the instantaneous fracture strain in that increment. D0-D5 parameters can be calculated using the experiments of hot and room temperature tensile test and drawing the fracture strain against temperature.

$D=\sum_{i} \frac{\Delta \varepsilon_{i}^{p}}{\varepsilon_{f_{i}}^{p}}$

$\varepsilon_{f_{0}}^{p}=\mathrm{d}_{0}+\mathrm{d}_{1} \mathrm{~T}^{1}+\mathrm{d}_{2} \mathrm{~T}^{2}+\mathrm{d}_{3} \mathrm{~T}^{3}+\mathrm{d}_{4} \mathrm{~T}^{4}+\mathrm{d}_{5} \mathrm{~T}^{5}$

The AdvantEdge software has capability to model a focused location area where heat exchange can be focused on the workpiece and tool and it can also move with the cutting process. The location of jet radius is kept at the cryogenic temperature of liquid nitrogen $(-180 \sim-190$ $\mathrm{C}^{\circ}$ ). When modeling the cryogenic cooling process, jet radius and jet location are two important parameters. To

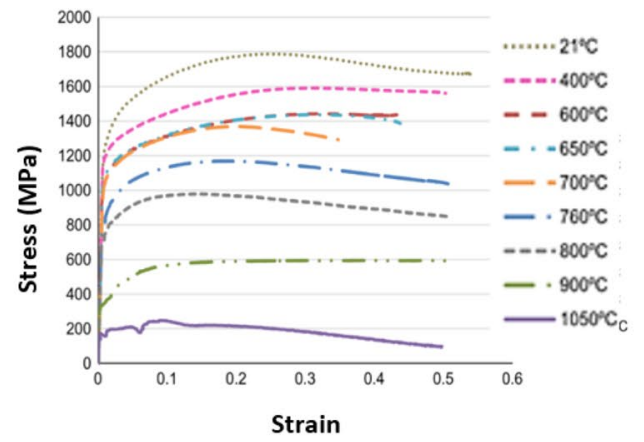

(a)

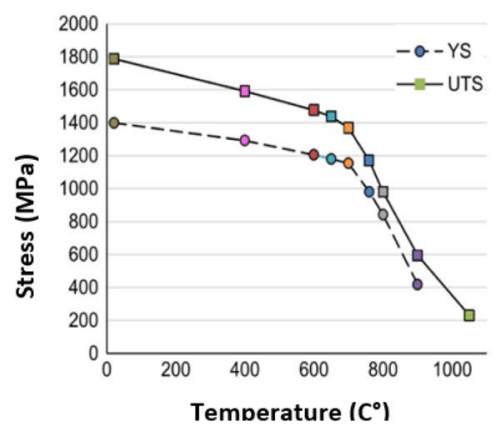

(b)
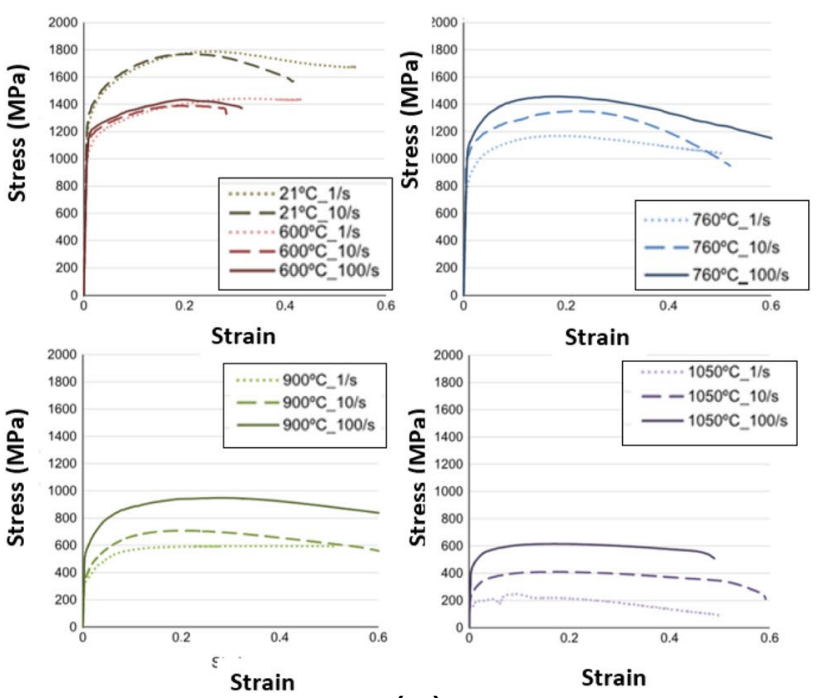

(c)

Fig. 5 Flow stress behavior of Inconel 718. a Testing at various temperatures at strain rate of $1 \mathrm{~s}^{-1}$. b Thermal softening behavior. $\mathbf{c}$ Temperature influence with respect to the various strain rates (obtained from [23] with kind permission from Elsevier)

simulate the cryogenic cooling in the model, a focused location window with convection cooling was set up centered on the workpiece. The environmental ambient temperature was set to $20^{\circ} \mathrm{C}$ besides the location of jet radius that was kept at $-190{ }^{\circ} \mathrm{C}$. As per the available literature [31], the study utilized jet radius of $1 \mathrm{~mm}$, heat transfer 


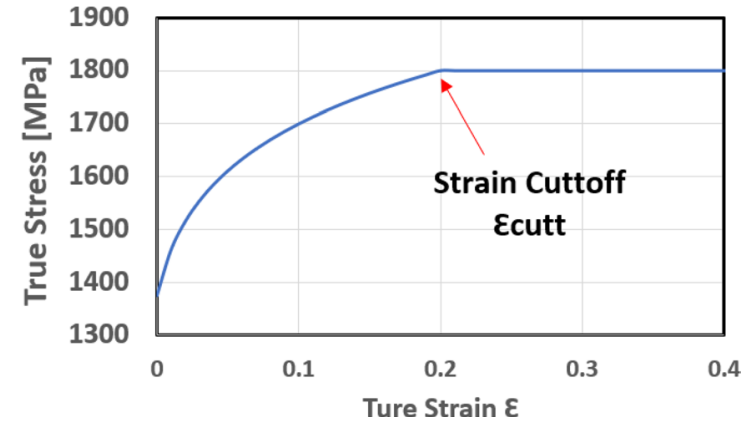

(a)

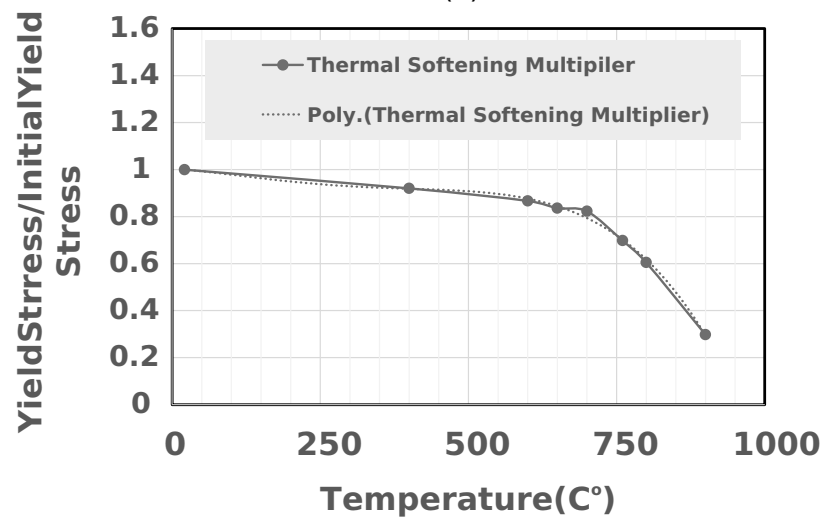

(b)

Fig. 6 Inconel 718 parameters for finite element model. a Strain hardening behavior. $\mathbf{b}$ Thermal softening behavior

coefficient of $5000 \mathrm{~kW} / \mathrm{m}^{2} \mathrm{~K}$, and jet location $(3,5) \mathrm{mm}$ for all cryogenic cutting simulations. Tool and workpiece have tendency to exchange heat with environment in the specified window, and heat conduction was allowed at the tool chip interface as shown in Fig. 8. The envelope shown along the workpiece is referred as heat exchange area, and initially cutting tool is maintained at the ambient temperature. Figure 9 represents the sample simulation for cryogenic cutting.

To utilize the full potential of FE numerical model, the model was first validated by the experimental data obtained by the measuring the experimental cutting force for all experiments and chip morphology was also examined under the light microscope for two conditions of cryogenic machining and dry cutting each.

Table 3 Constants for the advanced power law-based material model

\begin{tabular}{llllll}
\hline$\sigma 0(\mathrm{MPa})$ & $\mathrm{n}$ & $\varepsilon_{o}^{p}$ & $\mathrm{Tm}\left(\mathrm{C}^{\circ}\right)$ & $\mathrm{Tcut}\left(\mathrm{C}^{\circ}\right)$ & $\mathrm{m} 1$ \\
\hline 1375 & 11.3 & 0.01 & 1420 & $-4 \mathrm{E}-12$ & 100 \\
C0 & C1 & C2 & C3 & C4 & C5 \\
1.004 & $-2 \mathrm{E}-3$ & $-1 \mathrm{E}-6$ & $5 \mathrm{E}-9$ & $-4 \mathrm{E}-12$ & 0 \\
D0 & D1 & D2 & D3 & D4 & D5 \\
1.1404 & $8 \mathrm{E}-4$ & $3 \mathrm{E}-20$ & 0 & 0 & 0 \\
\hline
\end{tabular}

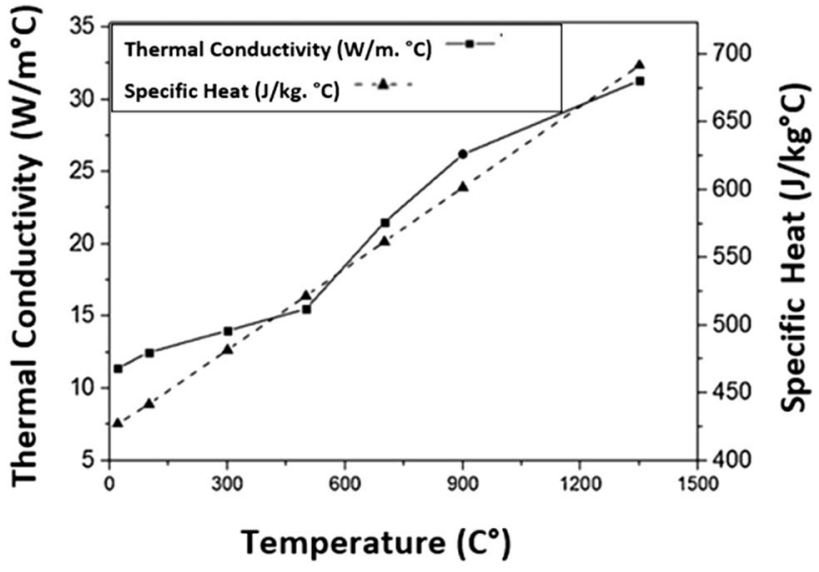

Fig. 7 Thermal conductivity and heat capacity of Inconel 718 as a function of temperature (adopted from [30] with kind permission from Elsevier)

Figure 10a represents the average values of experimental and simulated cutting forces. Figure $10 \mathrm{~b}$ represents the chips obtained and developed by experiment and simulations, respectively. It is mentioned in the literature that FEM predictions are mostly on the lower side when compared with the experimental readings. One major flaw is due to the imperfections involved in model friction at the tool chip interface. Astakhov [32] attributed this because workpiece is modelled as perfectly plastic and isotropic through the deformation phase. In addition, the material is always modelled without the influence of residual stresses due to previous processing. The model and experimental readings for average valleys and average peaks were found in good agreement with errors less than $12.2 \%$ and $10.4 \%$ respectively.

\section{Results and discussion}

\subsection{Effect on chip compression ratio, shear angle, and contact length}

To analyze the performance and plastic deformation in the cutting process, chip compression ratio is attributed as a key quantitative measure. The procedure is based on calculating chip compression ratio from the experimental observations of chips obtained during experimentation [33]. The chip is generally formed due to the formation of localized shear zone ahead of cutting edge. The excessive shearing happens in a very narrow planer zone oriented at an angle namely shear angle. Shear angle is also one of the major cutting parameters; once it is calculated, all other parameters can be calculated as well. Generally, shear angle has a controlling influence on the cutting forces. Based on the basic 


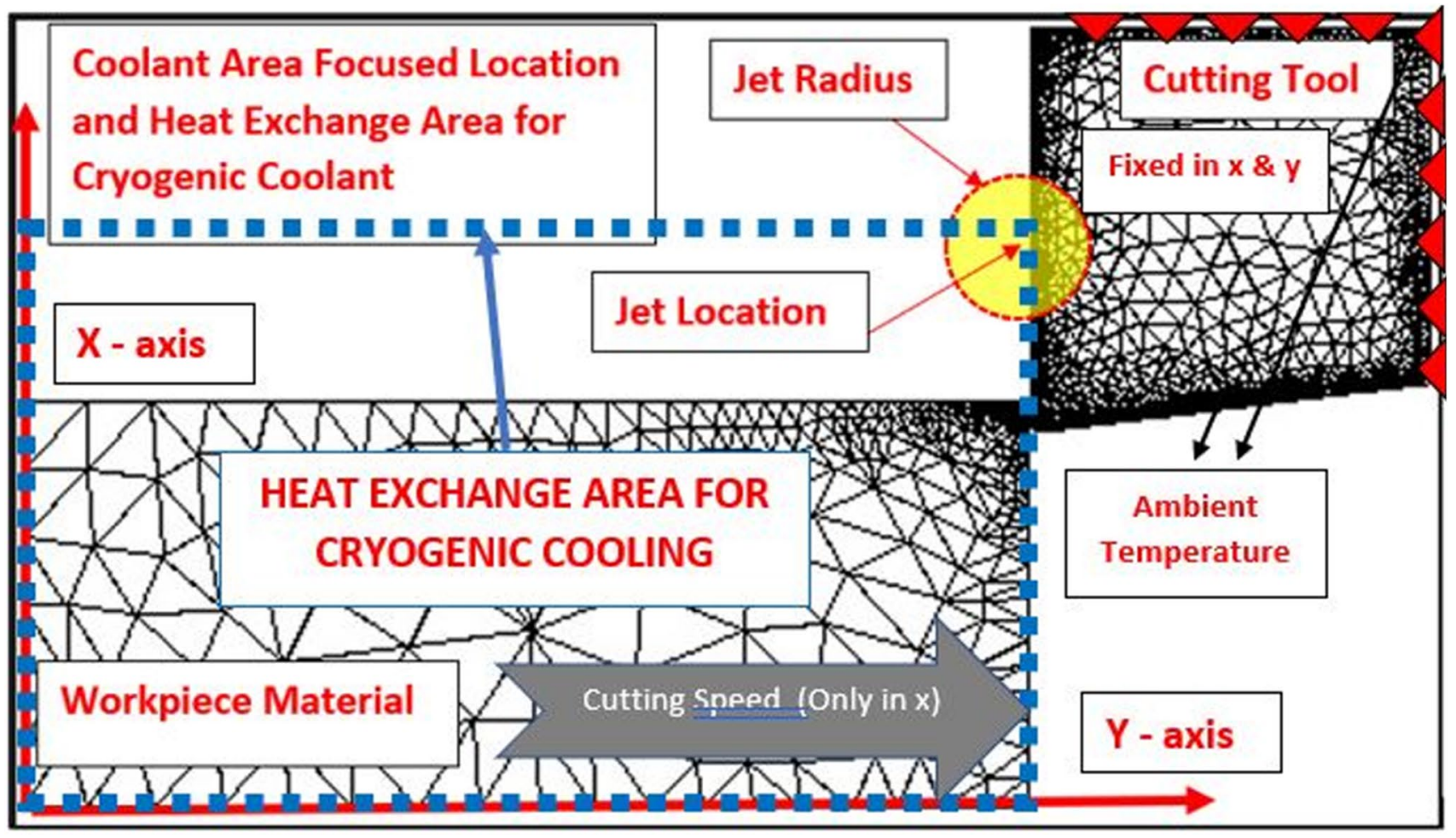

Fig. 8 FE model setup utilized for the cryogenic machining

Fig. 9 A sample of simulation for cryogenic cooling, cutting speed of $90 \mathrm{~m} / \mathrm{min}$, and undeformed chip thickness of $0.1 \mathrm{~mm} / \mathrm{rev}$

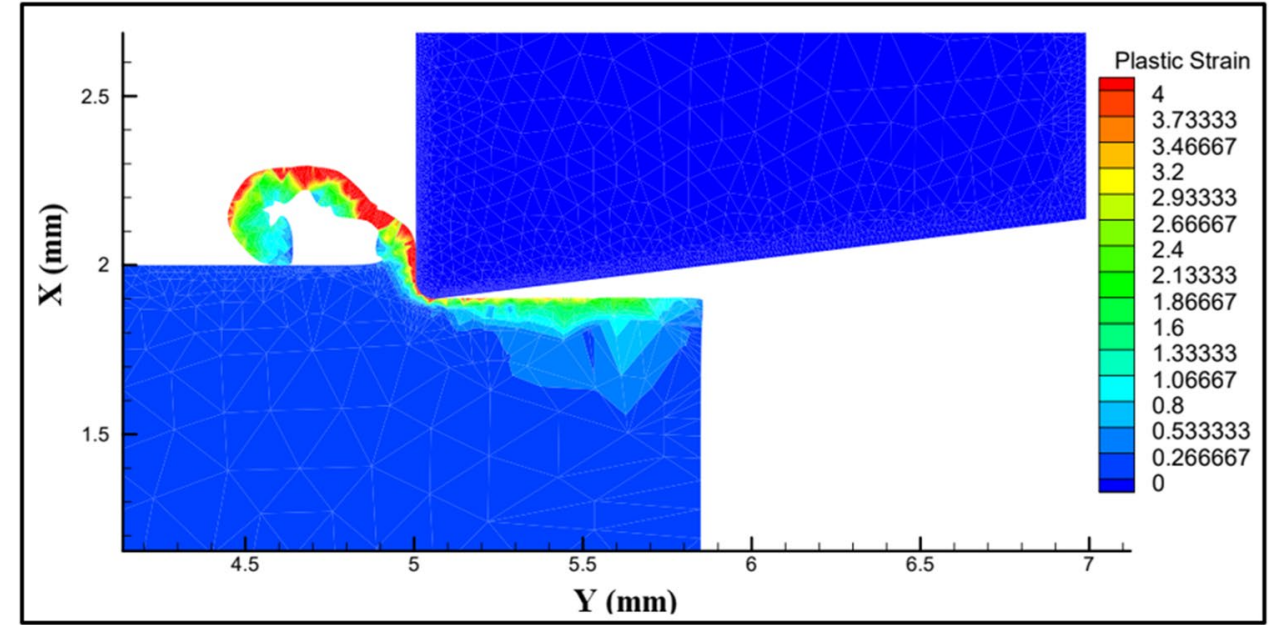

orthogonal cutting mechanics, below Eqs. 17 and 18 were employed to calculate the shear angle $(\varphi)$ and chip compression ratio $(\zeta)$ using the simulated data [34-36]. Several researchers have incorporated similar methodology to utilize experimental and simulated data for machining performance evaluation [24, 27, 37-39].

Chip compression $\operatorname{ratio}(\zeta)=\frac{\mathrm{a}_{\mathrm{ch}}}{\mathrm{a}_{\mathrm{c}}}$
Shear angle $(\varphi)=\arctan \frac{\cos \gamma_{o}}{\zeta-\sin \gamma_{o}}$

Figure 8 a and b compare the calculated results for chip compression ratio under dry and cryogenic cutting conditions. It was observed that higher chip compression ratio was obtained under dry cutting as compared to the cryogenic cutting environment. As shown in Fig. 11b, at cutting speed of $90 \mathrm{~m} / \mathrm{min}$, the chip compression ratio was reduced in the cryogenic cutting by $3.7 \%, 10.5 \%$, and $6 \%$ for undeformed 
Fig. 10 a Experimental and simulated cutting force component under cryogenic cooling. b Dry cutting, cutting speed $=90 \mathrm{~m} / \mathrm{min}$ and feed $=0.15 \mathrm{~mm} / \mathrm{rev}$.
- Cryo_Exp_Fc(N) s Cryo_Sim_Fc(N)

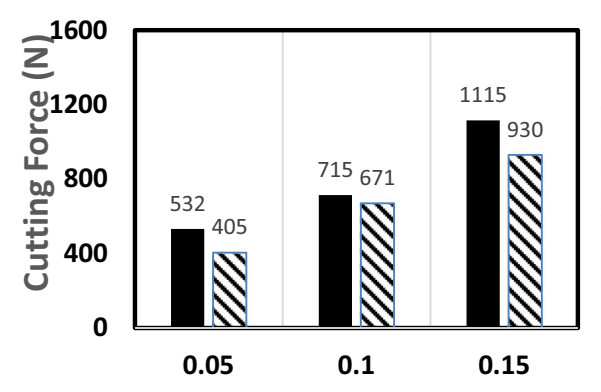

Undeformed chip thickness $(\mathrm{mm})$

(a)

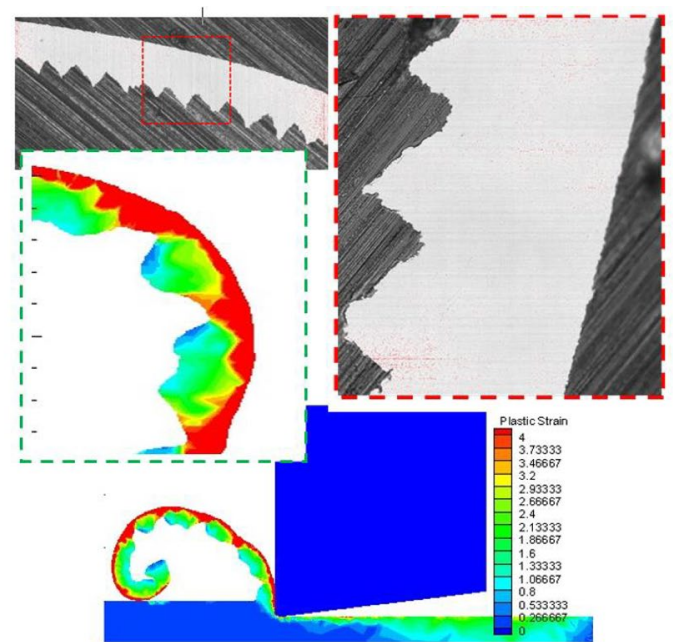

(b) chip thickness of $0.05,0.10$, and $0.15 \mathrm{~mm}$, respectively. The reduction in the chip compression ratio for cryogenic cutting is linked with comparatively reduced coefficient of friction at the tool chip contact. Lower frictional contact at the tool chip interface reduces cutting temperature and results in overall better lubrication. Similarly, in Fig. 11a, a common trend has been observed for both dry and cryogenic cutting that when cutting speed increases the chip compression ratio decreases. This trend is linked with the generation of thicker chips at the low cutting speed. The generation of thick chips at low cutting speeds can be verified by the low value of shear plane angle as shown in Fig. 11c. The lower shear plane angle results in higher contact area at the tool chip interface. However, increasing the cutting speed results in increasing the shear plane angle and lower contact area with lower value of chip compression ratio. Similar phenomenon was experienced by other researchers as well in their work [40].

To understand the cutting performance with respect to the secondary deformation zone at the cutting tool-chip interface, cutting length plays a significant role. During chip formation, the material being cut exerts cutting force on a small length at the rake face. The contact length value further develops understanding of cutting forces, chip formation, tool wear, and linked tool wear mechanisms. As per the available literature [41], the contact length at the tool-chip contact can be calculated by Eq. 19 using the chip compression ratio, provided that chip compression ratio is less than 4. It was observed in Fig. $12 \mathrm{a}$ and $\mathrm{b}$ that contact length was higher in the dry cutting as compared to the cryogenic cutting. The reason can be linked with the lower value of shear angles and resulting higher coefficient of friction in the dry cutting. Figure $12 \mathrm{c}$ represents the overlay plot of both chip formations during dry and cryogenic cutting. It can be observed that average chip thickness of dry cutting is comparatively larger than the one obtained in cryogenic cutting.

$1_{c}=a_{c} * \zeta^{1.5}$

\section{Cutting forces and specific cutting energy analysis}

In the metal cutting operation, forces are generated to cut material. Cutting forces are generally utilized as an important indicator to predict machinability of cutting process. The component of machining force acting in the direction of cutting velocity is termed as main cutting force component and contributes majorly towards the power and energy consumed in the cutting process. In this work because power and energy consumption were to be calculated, only the main cutting force component is employed. Figure 13 $a$ and $b$ show experimental and simulated results of cutting forces. There was a reasonable agreement between the experimental data and simulated results. Error margin between the experimental and simulated data was less than $20 \%$ for all conditions except one condition (dry cutting, $90 \mathrm{~m} / \mathrm{min}$ and $0.15 \mathrm{~mm}$ ) where the error jumped up to the $30 \%$. The simulated results are generally towards the lower bound when compared with the experimental data, and possible reasons have been discussed in the literature [32]. These variations in the forces are because the workpiece material is modelled as perfect plastic material and ignores any pre-stressed conditions available in the component in the form of residual stresses. Both experimental and simulated forces were found slightly lower in cryogenic cutting. Lower forces in the cryogenic cutting represent efficient cooling action that resulted in reducing the coefficient of friction at 
Fig. 11 Dry and cryogenic simulated cutting. a Chip compression ratio vs. cutting speed at undeformed chip thickness of $0.05 \mathrm{~mm}$. b Chip compression ratio vs. undeformed chip thickness at cutting speed of $90 \mathrm{~m} / \mathrm{min}$. c Shear plane angle vs. cutting speed at undeformed chip thickness of $0.05 \mathrm{~mm}$

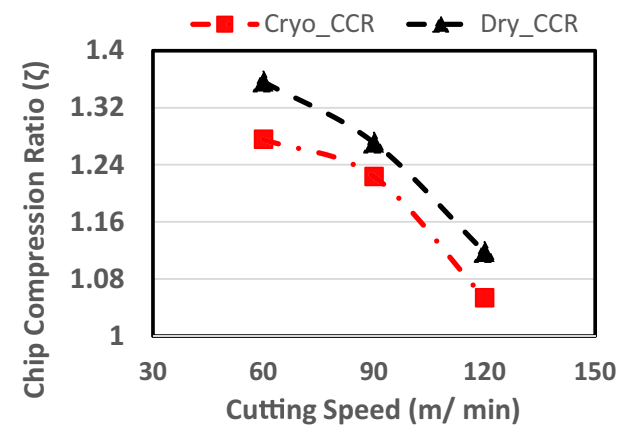

(a)

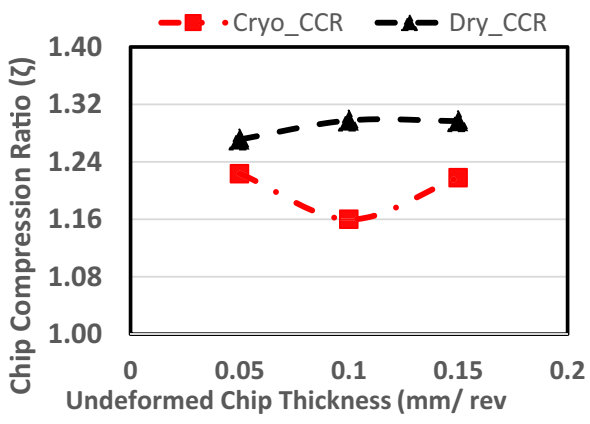

(b)

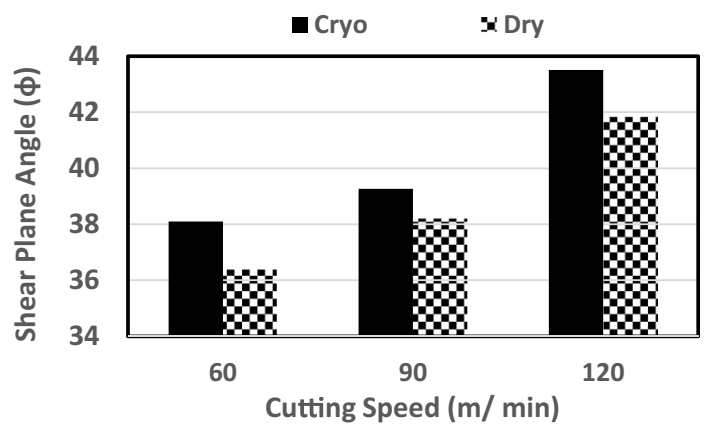

(c)

the tool chip interface. Previous observations of shear angle and contact length also point out at lower cutting forces in cryogenic environment.

Power consumed in the cutting process can be computed using Eq. 20. Another important derivative of cutting force is called as specific cutting energy. Specific cutting energy (SCE) is the amount of energy required to cut unit volume of workpiece material. Specific cutting energy (SCE) is composed of cutting power with respect to the cutting conditions involved. Equations 21 and 22 can be employed to calculate the specific cutting energy (SCE).

$\mathrm{P}_{\text {consumed }}=\mathrm{F}_{\mathrm{c}} \mathrm{v}$

$\mathrm{SCE}=\frac{\mathrm{P}_{\text {consumed }}}{\mathrm{MRR}}$

$\mathrm{SCE}=\frac{\mathrm{F}_{\mathrm{c}}}{\mathrm{A}_{\mathrm{c}}}$

where MRR is the material removal rate $(v x f \mathrm{x} d)$ and Ac is the undeformed chip thickness area that can be calculated by undeformed chip thickness and width of cut. Figure 14 represents the specific cutting energy (SCE) calculated for cryogenic and dry cutting environments. It can be seen that higher SCE was observed for lower value of undeformed chip thickness under both dry and cryogenic cutting environments. It is due to the presence of plowing force at low value of undeformed chip thickness. This phenomenon is referred as size effect in the metal cutting literature [42].

\section{Analysis of chip morphology}

The experimental and simulated chip formation was examined by measuring the peaks, valleys, and pitch distances measured as per the schematic illustration below. As per the guidelines mentioned in literature [38, 43-45], segmentation ratio (SR) was computed to examine the experimental and simulated chip formations for all cutting tests. Segmentation ratio (SR) is computed by taking the ratio of difference in peak to valley over the peak as per the schematic diagram in Fig. 15 and Eq. 16. Average values of peak and valley were considered from 4 to 5 repetitive measurements. The peak value of chip thickness shows excessive deformation under shear and is dependent on the workpiece material strength [43]. However, the valley value of chip thickness creates the segment assisted by fracture. The difference between peak and valley shows the plastic deformation involved in the segment [43]. To validate the simulated chip morphologies, four random experimental chips were examined and found in good agreement with the simulated results.

Chip Segmentation Ration(SR), (SR) $=\frac{\mathrm{t} 1-\mathrm{t} 2}{\mathrm{t} 1}$ 
Fig. 12 Dry and cryogenic simulated cutting. a Contact length vs. cutting speed at undeformed chip thickness of $0.05 \mathrm{~mm}$. b Contact length vs. undeformed chip thickness at cutting speed of $90 \mathrm{~m} / \mathrm{min}$. c Overlay plot of both dry and cryogenic cutting simulations at cutting speed $=90 \mathrm{~m} / \mathrm{min}$ and undeformed chip thickness $=0.05 \mathrm{~mm}$

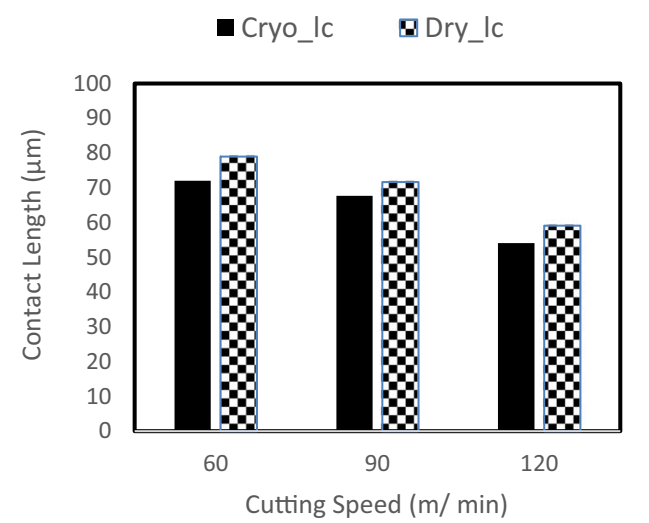

(a)

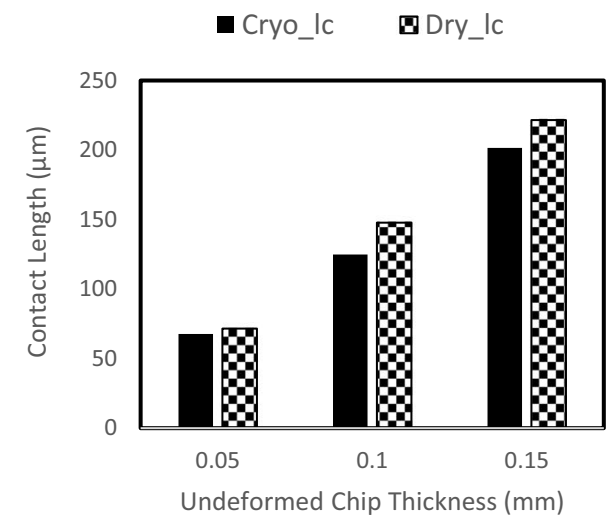

(b)

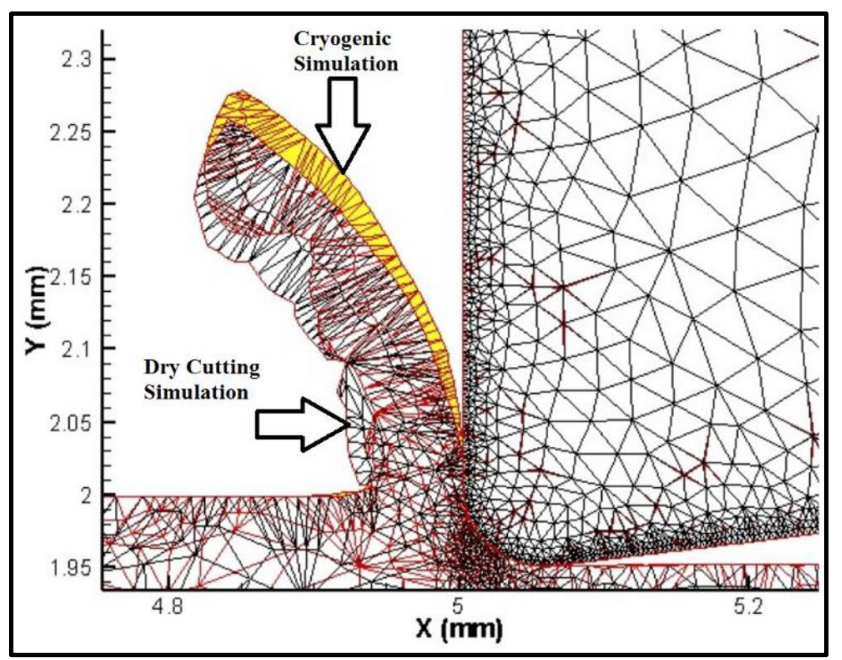

(c)

Fig. 13 Experimental and simulated dry and cryogenic cutting forces. a Cryogenic cutting force vs. undeformed chip thickness. b Dry cutting force vs. undeformed chip thickness

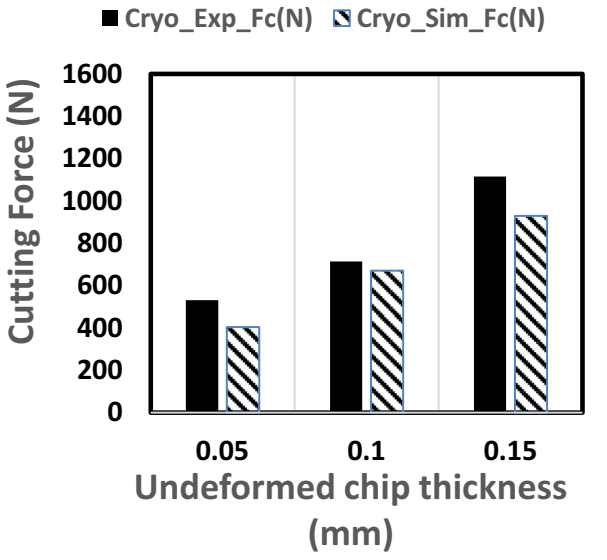

(a)

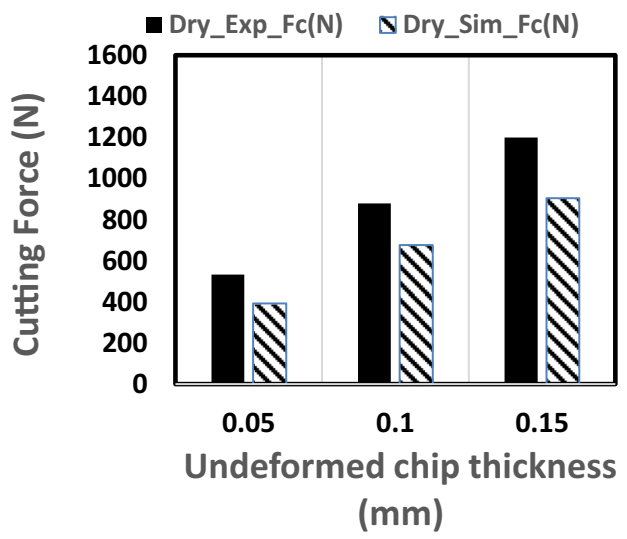

(b)
Figure 16 represents the sample calculation work performed to compare the chip morphologies and associated analysis between experimental and simulated chips. Several measurements of peaks ( $\mathrm{t} 1)$, valleys ( $\mathrm{t} 2)$, and pitches $(\mathrm{P})$ were calculated, and then average values were represented in Table 4. Error was below $10.4 \%$ for the average peak 
Fig. 14 Specific cutting energy (SCE) vs. different undeformed chip thicknesses at cutting speed of $90 \mathrm{~m} / \mathrm{min}$

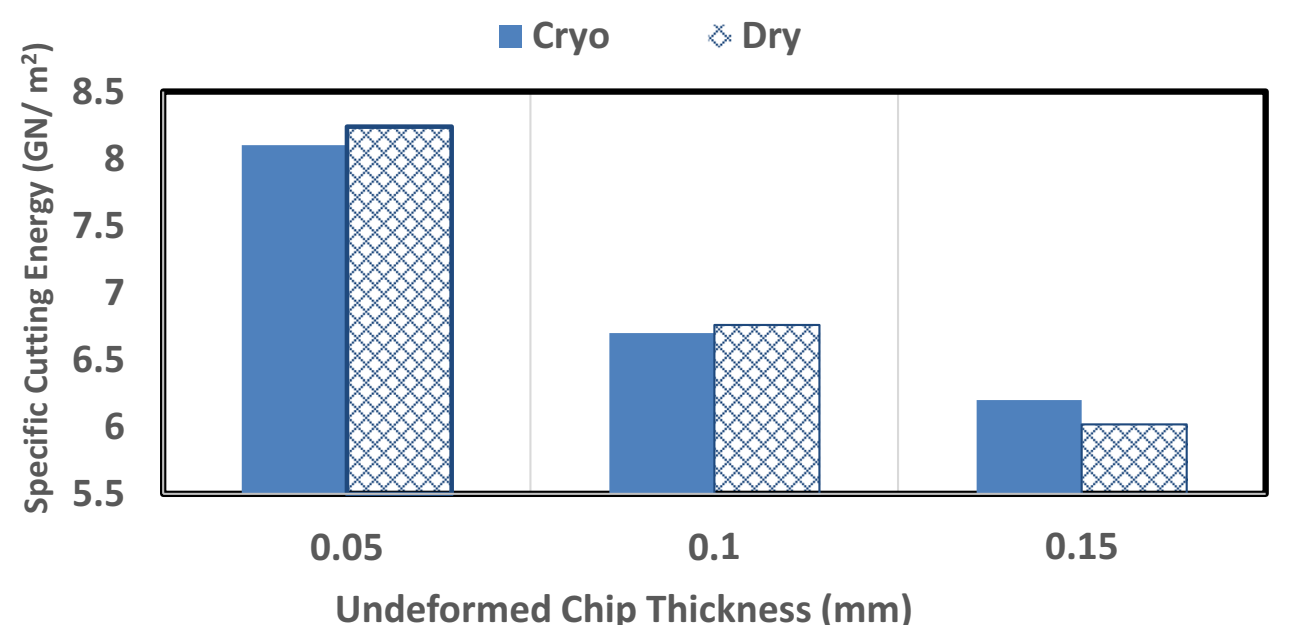

Different chip morphologies under dry cutting and cryogenic cooling are presented in Fig. 17 a, b, and c. In both dry and cryogenic cutting, chip morphology parameters such as peaks, valleys, and pitches increase by increasing the undeformed chip thickness. Literature points out that peak values are associated with the deformation of

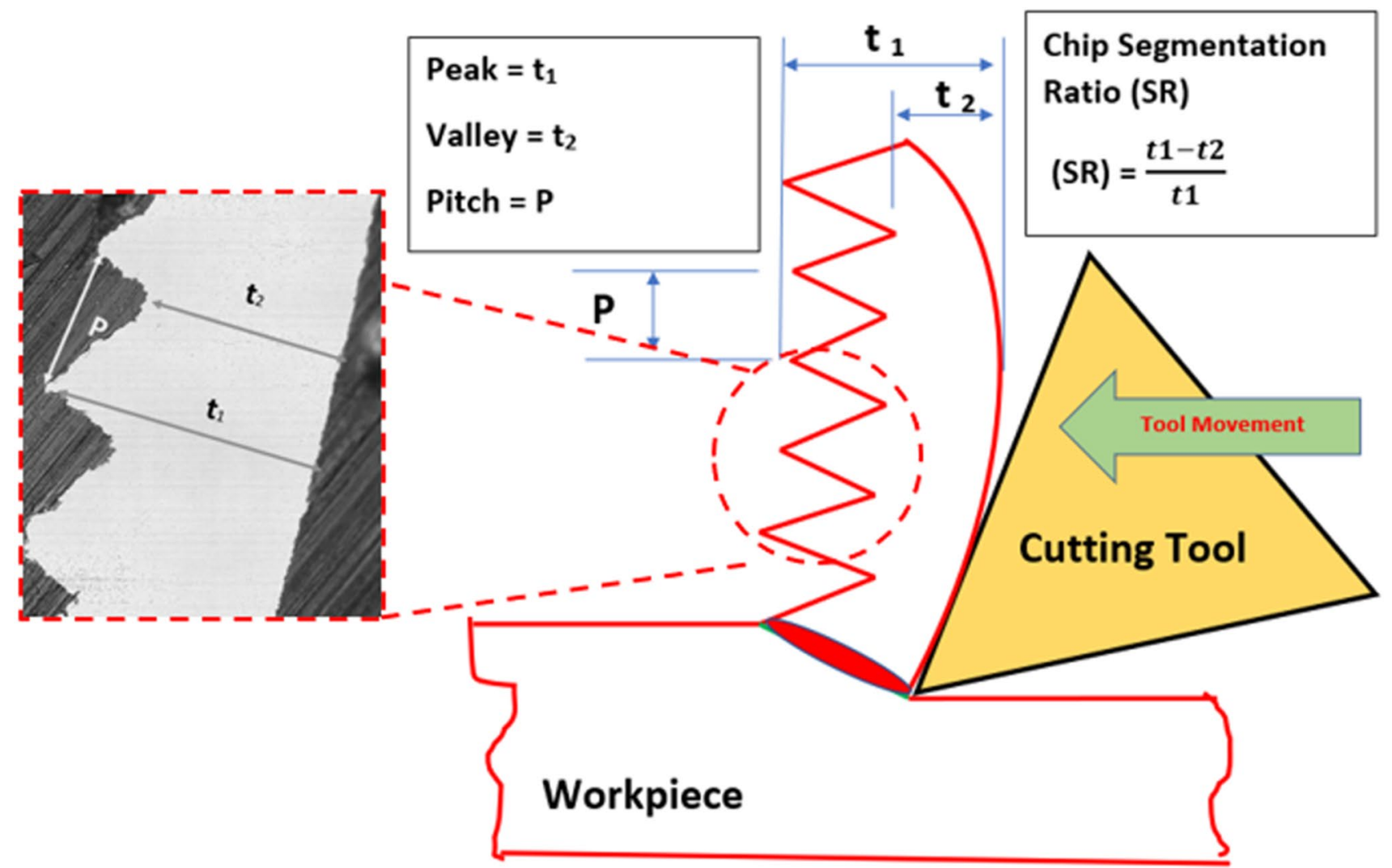

Fig. 15 Schematic illustration of segmented chip formed and definitions of chip morphology during the cutting process 
Fig. 16 Sample calculation work performed for cryogenic cutting (cutting speed $=90 \mathrm{~m} /$ min and undeformed chip thickness $=0.05 \mathrm{~mm}$ )

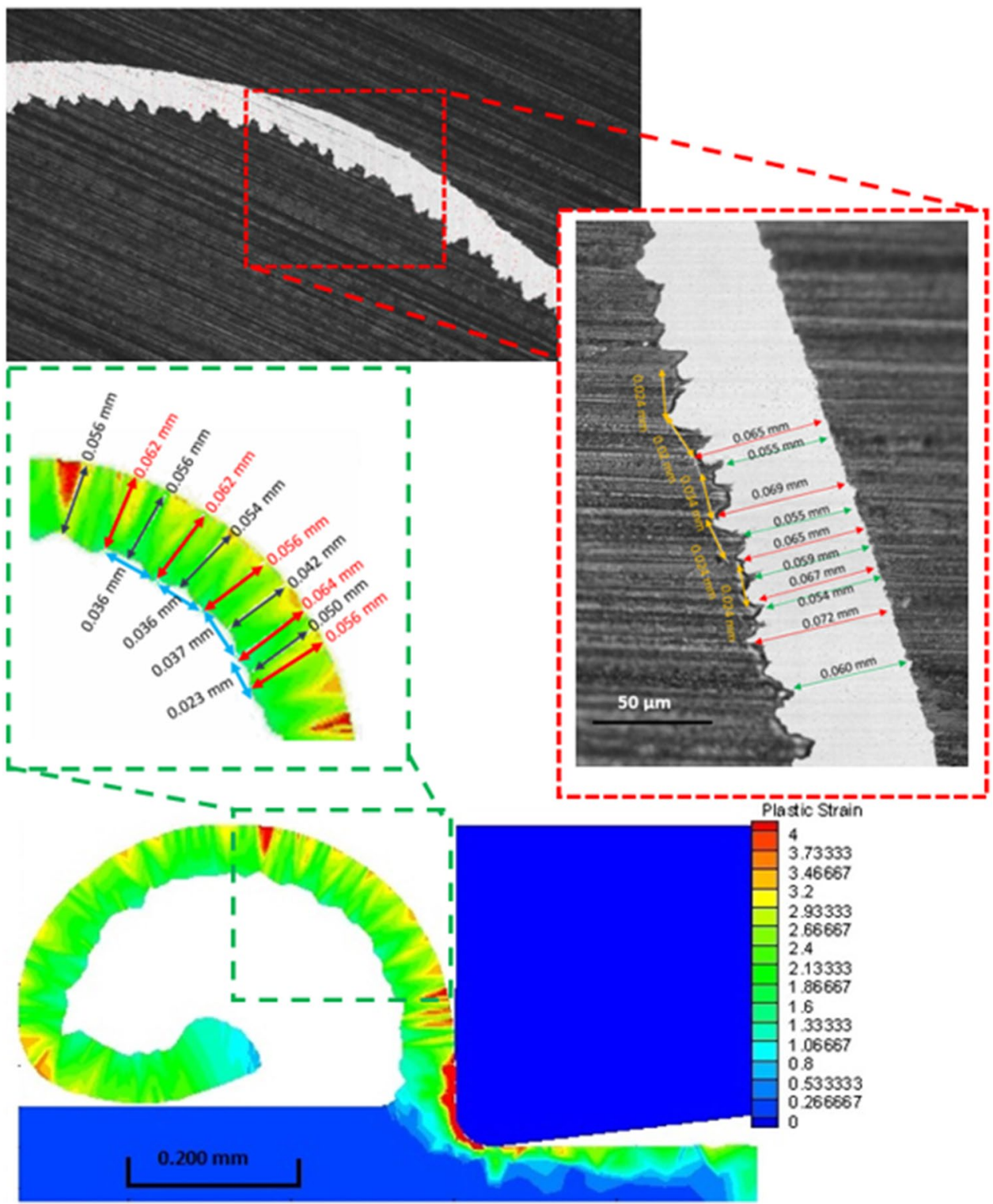

Table 4 Comparison of parameters related to chip morphology from simulated and experimental data

\begin{tabular}{lllll}
\hline Cutting conditions & & \multicolumn{2}{l}{ Chip morphology $(\mathrm{mm})$} & \\
\cline { 3 - 5 } & & Average peak & Average valley & Average pitch \\
\hline Test 1 - Cryogenic & Experimental & 0.067 & 0.057 & 0.026 \\
Vc=90 m/min & Numerical & 0.060 & 0.050 & 0.032 \\
$\mathrm{f}=0.05 \mathrm{~mm} / \mathrm{rev}$ & Error $\%$ & $+10.4 \%$ & $+12.2 \%$ & $-23 \%$ \\
Test $5-\mathrm{Cryogenic}$ & Experimental & 0.053 & 0.034 & 0.043 \\
$\mathrm{Vc}=120 \mathrm{~m} / \mathrm{min}$ & Numerical & 0.057 & 0.036 & 0.054 \\
$\mathrm{f}=0.05 \mathrm{~mm} / \mathrm{rev}$ & Error $\%$ & $-7.5 \%$ & $-5.8 \%$ & $-25.6 \%$ \\
Test $6-\mathrm{Dry}$ & Experimental & 0.058 & 0.045 & 0.0515 \\
$\mathrm{Vc}=90 \mathrm{~m} / \mathrm{min}$ & Numerical & 0.061 & 0.047 & 0.0395 \\
$\mathrm{f}=0.05 \mathrm{~mm} / \mathrm{rev}$ & Error $\%$ & $-5.17 \%$ & $-4.4 \%$ & $-30.4 \%$ \\
Test $8-\mathrm{Dry}$ & Experimental & 0.148 & 0.107 & 0.129 \\
$\mathrm{Vc}=90 \mathrm{~m} / \mathrm{min}$ & Numerical & 0.156 & 0.0970 & 0.167 \\
$\mathrm{f}=0.15 \mathrm{~mm} / \mathrm{rev}$ & Error $\%$ & $-5.4 \%$ & $+9.3 \%$ & $-22.75 \%$ \\
\hline
\end{tabular}


Fig. 17 Chip morphology of Inconel 718 at cutting speed of $90 \mathrm{~m} / \mathrm{min}$ under various feed rates. a Cryogenic cooling. b Dry cutting. c Chip segmentation ratio for both cryogenic and dry machining

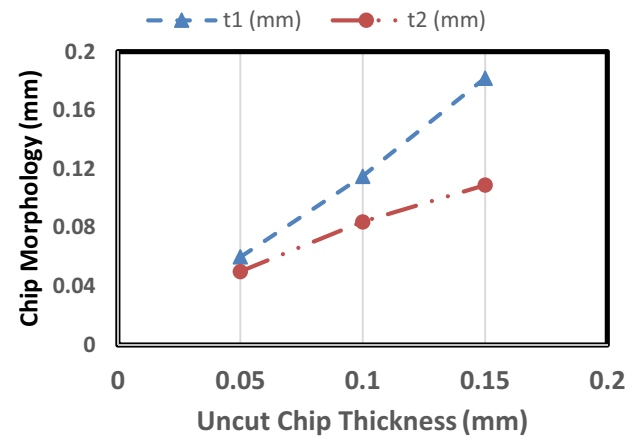

(a)

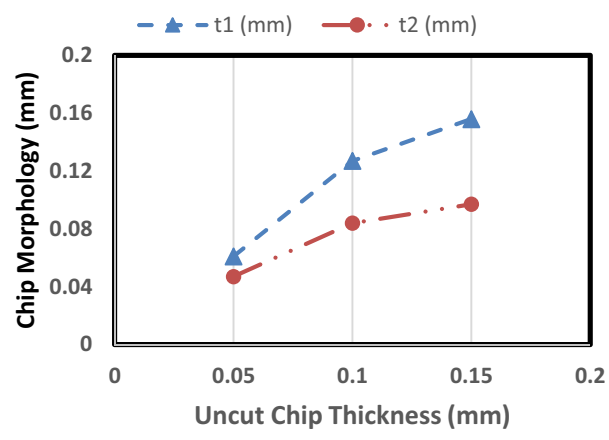

(b)

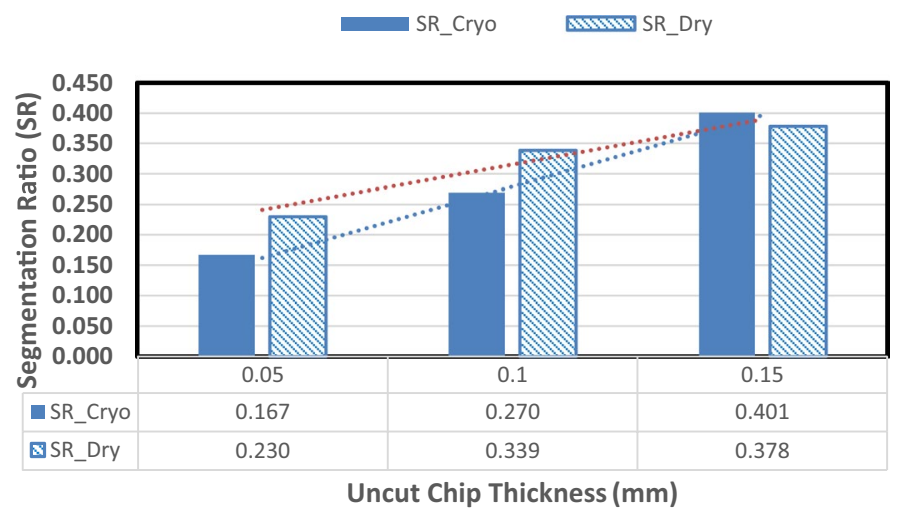

(c)

workpiece materials under shear [43]. Higher value of peaks with increasing undeformed chip thickness represents that there is more shear deformation present. Segmented chip is formed due to development of shear band due to the simultaneous presence of thermal softening and strain hardening in workpiece material. When analyzed in detail, it is observed that grains experience excessive shear deformation resulting in the segmented chips. Chip segmentation is the result of two mechanisms; the interconnected portion between two chip segments experiences excessive plastic strain. The portion that separates and hangs outside on the free surface is the result of fracture. It is also reported that during the process two segments slide on each other resulting in saw tooth shape. The sliding takes place under shear load and fracture between the segment is observed to be type II (in-plane shear) fracture. Chip segmentation ratio (SR) is widely used to measure the extent of these mechanisms in the segmented chips. By utilizing the peaks and valleys, chip segmentation ratio (SR) can be calculated as pointed out in Fig. 15 and Eq. 16. Chip segmentation ratio was found higher when undeformed chip thickness increases. Higher value of segmentation ratio is due to the higher difference in peak and valley values, which means that the length of chip segment where fracture takes place is longer as compared to the length segment with severe plastic strain. Lower values of chip segmentation were observed at low levels of undeformed chip thickness for cryogenic machining as compared to the dry cutting. It can be attributed due to improved cooling and lubrication as seen and discussed in the previous sections. However, at higher level of undeformed chip thickness, chip segmentation ratio was found higher in cryogenic cooling as compared to dry cutting. It can be attributed to the strain hardening of Inconel 718 and dominant thermal softening of dry cutting.

\section{Conclusions}

Following conclusions are drawn from this study.

- The chip compression ratio was decreased in the cryogenic cutting by $3.7 \%, 10.5 \%$, and $6 \%$ for undeformed chip thickness of $0.05,0.10$, and $0.15 \mathrm{~mm}$, respectively. The reduction in the chip compression ratio for cryogenic cutting is linked with comparatively reduced coefficient of friction at the tool chip contact. Lower frictional contact at the tool chip interface reduces cutting temperature and results in overall better lubrication.

- A generic trend was observed for both dry and cryogenic cutting that when cutting speed increases the chip com- 
pression ratio decreases. It is linked with the generation of thicker chips at low cutting speed. The generation of thick chips at low cutting speeds can be verified by the low value of shear plane angles.

- The contact length was higher in the dry cutting as compared to the cryogenic cutting. It was also observed that average chip thickness of dry cutting is larger than the one obtained in cryogenic cutting. The reason can be linked with the lower value of shear angles and resulting higher coefficient of friction in the dry cutting.

- The variations in forces are because the workpiece material is modelled as perfect plastic material and ignores any pre-stressed conditions available in the component in the form of residual stresses. Both experimental and simulated forces were found slightly lower in cryogenic cutting. Lower forces in the cryogenic cutting represent efficient cooling action that resulted in reducing the coefficient of friction at the tool chip interface.

- Higher specific cutting energy (SCE) was observed for lower value of undeformed chip thickness under both dry and cryogenic cutting environments. It is due to the presence of plowing force at low value of undeformed chip thickness. This phenomenon is referred as size effect.

- In both dry and cryogenic cutting, chip morphology parameters such as peaks, valleys, and pitches increase by increasing the undeformed chip thickness. Higher value of peaks with increasing undeformed chip thickness represents that there is more shear deformation present. Segmented chip is formed due to development of shear band due to the simultaneous presence of thermal softening and strain hardening in workpiece material.

- Reduction in chip segmentation ratio was observed at low levels of undeformed chip thickness for cryogenic machining when compared to the dry cutting. It can be attributed due to improved cooling and lubrication in the cryogenic machining.

\section{Appendix 1}

Table 5 Appendix

\begin{tabular}{llll}
\hline Test No & \multicolumn{1}{l}{ Cutting speed $(\mathrm{m} / \mathrm{min})$} & Feed $(\mathrm{mm} / \mathrm{rev})$ \\
\hline Cryo1 & 90 & 0.05 & \\
Cryo2 & 90 & 0.1 & \\
Cryo3 & 90 & 0.15 & \\
Cryo4 & 60 & 0.05 & \\
Cryo5 & 120 & 0.05 & \\
Dry1 & 90 & 0.05 & \\
Dry2 & 90 & 0.1 & \\
Dry3 & 90 & 0.15 \\
Dry4 & 60 & 0.05 & \\
Dry5 & 120 & 0.05 & \\
\hline
\end{tabular}

\section{Appendix 2}

Table 6 Technical specifications of Kistler multi-channel dynamometer 9129AA [46]

\begin{tabular}{ll}
\hline Technical data & Value \\
\hline Measurement range $(\mathrm{Fx}, \mathrm{Fy}$, and Fz) & $-10 \sim 10 \mathrm{kN}$ \\
Sensitivity Fx and Fz & $\approx-8 \mathrm{pC} / \mathrm{N}$ \\
Sensitivity Fx and $\mathrm{Fz}$ & $\approx-4,1 \mathrm{pC} / \mathrm{N}$ \\
Operating temperature range & $0-70{ }^{\circ} \mathrm{C}$ \\
$\mathrm{L} \times \mathrm{W} \times \mathrm{H}$ & $90 \times 105 \times 32 \mathrm{~mm}$ \\
Weight & $3.2 \mathrm{~kg}$ \\
Natural frequency, fn(x) & $\approx 3.5 \mathrm{kHz}$ \\
Natural frequency, fn(y) & $\approx 4.5 \mathrm{kHz}$ \\
Natural frequency, fn(z) & $\approx 3.5 \mathrm{kHz}$ \\
\hline
\end{tabular}

Acknowledgements The authors would like to acknowledge the support provided by Third Wave Systems by providing the license of AdvantEdge finite element software for machining simulations.

Funding The study was financially supported by Dubai Silicon Oasis Authority (DSOA), and Rochester Institute of Technology - Dubai (RIT-D).

\section{Declarations}

Ethics approval No ethical approval needed for this research.

Consent for publication All authors give their permission to participate and publish.

Conflict of interest The authors declare no competing interests.

Open Access This article is licensed under a Creative Commons Attribution 4.0 International License, which permits use, sharing, adaptation, distribution and reproduction in any medium or format, as long as you give appropriate credit to the original author(s) and the source, provide a link to the Creative Commons licence, and indicate if changes were made. The images or other third party material in this article are included in the article's Creative Commons licence, unless indicated otherwise in a credit line to the material. If material is not included in the article's Creative Commons licence and your intended use is not permitted by statutory regulation or exceeds the permitted use, you will need to obtain permission directly from the copyright holder. To view a copy of this licence, visit http://creativecommons.org/licenses/by/4.0/.

\section{References}

1. Hong SY, Zhao Z (1999) Thermal aspects, material considerations and cooling strategies in cryogenic machining. Clean Technol Environ Policy 1:107-116 
2. Shokrani A, Dhokia V, Muñoz-Escalona P, Newman ST (2013) State-of-the-art cryogenic machining and processing. Int J Comput Integr Manuf 26:616-648. https://doi.org/10.1080/09511 92X.2012.749531

3. Nouzil I, Pervaiz S, Kannan S (2021) Role of jet radius and jet location in cryogenic machining of Inconel 718: a finite element method based approach. Int J Interact Des Manuf 15:1-19. https://doi.org/10.1007/s12008-020-00703-7

4. De Bartolomeis A, Newman ST, Biermann D, Shokrani A (2021) State-of-the-art cooling and lubrication for machining Inconel 718. J Manuf Sci Eng 143:5. https://doi.org/10.1115/1. 4047842

5. Shah P, Bhat P, Khanna N (2021) Life cycle assessment of drilling Inconel 718 using cryogenic cutting fluids while considering sustainability parameters. Sustain Energy Technol Assessments 43:100950. https://doi.org/10.1016/j.seta.2020.100950

6. Chaabani S, Arrazola PJ, Ayed Y, Madariaga A, Tidu A, Germain G (2020) Comparison between cryogenic coolants effect on tool wear and surface integrity in finishing turning of Inconel 718. J Mater Process Technol 285:116780. https://doi.org/10. 1016/j.jmatprotec.2020.116780

7. Liu C, Wan M, Zhang W, Yang Y (2021) Chip formation mechanism of Inconel 718: a review of models and approaches. Chinese J Mech Eng 34:1. https://doi.org/10.1186/ s10033-021-00552-9

8. Pereira O, Celaya A, Urbikaín G, Rodríguez A, Fernández-Valdivielso A, de Noberto López LL (2020) CO2 cryogenic milling of Inconel 718: cutting forces and tool wear. J Mater Res Technol 9:8459-68. https://doi.org/10.1016/j.jmrt.2020.05.118

9. Shokrani A, Newman ST (2017) Hybrid cooling and lubricating technology for CNC milling of Inconel 718 nickel alloy. Procedia Manuf 11:625-632. https://doi.org/10.1016/j.procir.2018.08.291

10. Pusavec F, Kopac J (2009) Achieving and implementation of sustainability. Adv Prod Eng Manag 4:151-160

11. Bermingham MJ, Kirsch J, Sun S, Palanisamy S, Dargusch MS (2011) New observations on tool life, cutting forces and chip morphology in cryogenic machining Ti-6Al-4V. Int J Mach Tools Manuf 51:500-511. https://doi.org/10.1016/j.ijmachtools.2011. 02.009

12. Bagherzadeh A, Budak E (2018) Investigation of machinability in turning of difficult-to-cut materials using a new cryogenic cooling approach. Tribol Int 119:510-520. https://doi.org/10.1016/j.tribo int.2017.11.033

13. Pereira $\mathrm{O}$, Català $\mathrm{P}$, Rodríguez $\mathrm{A}$, Ostra $\mathrm{T}$, Vivancos $\mathrm{J}$, Rivero $\mathrm{A}$ et al (2015) The use of hybrid CO $2+\mathrm{MQL}$ in machining operations. Procedia Eng 132:492-499. https://doi.org/10.1016/j.proeng.2015.12.524

14. Stampfer B, Golda P, Zanger F, Schieß1 R, Maas U, Schulze V (2019) Thermomechanically coupled numerical simulation of cryogenic orthogonal cutting. Procedia CIRP 82:438-443. https:// doi.org/10.1016/j.procir.2019.04.036

15. Pu Z, Umbrello D, Dillon OW, Jawahir IS (2014) Finite element simulation of residual stresses in cryogenic machining of AZ31B Mg Alloy. Procedia CIRP 13:282-287. https://doi.org/10.1016/j. procir.2014.04.048

16. Ayed Y, Germain G, Melsio AP, Kowalewski P, Locufier D (2017) Impact of supply conditions of liquid nitrogen on tool wear and surface integrity when machining the Ti-6Al-4V titanium alloy. Int J Adv Manuf Technol 93:1199-1206. https://doi.org/10.1007/ s00170-017-0604-7

17. Khanna N, Agrawal C, Pimenov DY, Singla AK, Machado AR, da Silva LRR et al (2021) Review on design and development of cryogenic machining setups for heat resistant alloys and composites. J Manuf Process 68:398-422. https://doi.org/10.1016/j. jmapro.2021.05.053
18. De Bartolomeis A, Newman ST, Jawahir IS, Biermann D, Shokrani A (2021) Future research directions in the machining of Inconel 718. J Mater Process Technol 297:117260. https://doi. org/10.1016/j.jmatprotec.2021.117260

19. Deshpande YV, Andhare AB, Padole PM (2018) How cryogenic techniques help in machining of nickel alloys? A review Mach Sci Technol 22:543-584. https://doi.org/10.1080/10910344.2017. 1382512

20. Liu W, Ren D, Usui S, Wadell J, Marusich TD (2013) A gear cutting predictive model using the finite element method. Procedia CIRP 8:51-56. https://doi.org/10.1016/j.procir.2013.06.064

21. ThirdWaveSystems. Third Wave AdvantEdgeTM user's manual version 7.3. 2017

22. Man X, Ren D, Usui S, Johnson C, Marusich TD (2012) Validation of finite element cutting force prediction for end milling. Procedia CIRP 1:663-668. https://doi.org/10.1016/j.procir.2012. 04.119

23. Iturbe A, Giraud E, Hormaetxe E, Garay A, Germain G, Ostolaza K et al (2017) Mechanical characterization and modelling of Inconel 718 material behavior for machining process assessment. Mater Sci Eng A 682:441-453. https://doi.org/10.1016/j.msea. 2016.11.054

24. Ebrahimi SM, Araee A, Hadad M (2019) Investigation of the effects of constitutive law on numerical analysis of turning processes to predict the chip morphology, tool temperature, and cutting force. Int J Adv Manuf Technol 105:4245-4264

25. Laakso SVA, Niemi E (2016) Modified Johnson-Cook flow stress model with thermal softening damping for finite element modeling of cutting. Proc Inst Mech Eng Part B J Eng Manuf 230:241-253. https://doi.org/10.1177/0954405415619873

26. Chen F, Liu J, Ou H, Lu B, Cui Z, Long H (2015) Flow characteristics and intrinsic workability of IN718 superalloy. Mater Sci Eng A 642:279-287. https://doi.org/10.1016/j.msea.2015.06.093

27. Maranhão C, Davim JP (2010) Finite element modelling of machining of AISI 316 steel : Numerical simulation and experimental validation. Simul Model Pract Theory 18:139-156. https:// doi.org/10.1016/j.simpat.2009.10.001

28. Erice B, Pérez-Martín MJ, Gálvez F (2014) An experimental and numerical study of ductile failure under quasi-static and impact loadings of Inconel 718 nickel-base superalloy. Int J Impact Eng 69:11-24. https://doi.org/10.1016/j.ijimpeng.2014.02.007

29. Haq IU, Weiguo G, Arif M, Sheikh MZ (2018) Study of various conical projectiles penetration into Inconel-718 target. Procedia Struct Integr 13:1955-1960. https://doi.org/10.1016/j.prostr.2018. 12.265

30. Baek JT, Woo WS, Lee CM (2018) A study on the machining characteristics of induction and laser-induction assisted machining of AISI 1045 steel and Inconel 718. J Manuf Process 34:513-522. https://doi.org/10.1016/j.jmapro.2018.06.030

31. Davoudinejad A, Chiappini E, Tirelli S, Annoni M, Strano M (2015) Finite element simulation and validation of chip formation and cutting forces in dry and cryogenic cutting of Ti-6Al- $4 \mathrm{~V}$. Procedia Manuf 1:728-739. https://doi.org/10.1016/j.promfg.2015. 09.037

32. Astakhov VP (2006) Tribology of metal cutting. Tribol Met Cut 52:227. https://doi.org/10.1016/S0167-8922(06)80005-2

33. Astakhov VP, Shvets S (2004) The assessment of plastic deformation in metal cutting. J Mater Process Technol 146:193-202. https://doi.org/10.1016/j.jmatprotec.2003.10.015

34 Merchant ME (1945) Mechanics of the metal cutting process. I. Orthogonal cutting and a type 2 chip. J Appl Phys 16:267-75. https://doi.org/10.1063/1.1707586

35 Merchant ME (1945) Mechanics of the metal cutting process. II. Plasticity conditions in orthogonal cutting. J Appl Phys 16:318. https://doi.org/10.1063/1.1707596 
36. Piispanen V (1948) Theory of formation of metal chips. J Appl Phys 19:876. https://doi.org/10.1063/1.1697893

37. Kumar A, Maity K (2019) Analysis of some critical aspects in hot machining of Ti-5553 superalloy : experimental and FE analysis. Def Technol 15:344-352. https://doi.org/10.1016/j.dt.2018.10.005

38. Chen G, Ren C, Yang X, Jin X, Guo T (2011) Finite element simulation of high-speed machining of titanium alloy (Ti-6Al$4 \mathrm{~V}$ ) based on ductile failure model. Int J Adv Manuf Technol 56:1027-1038. https://doi.org/10.1007/s00170-011-3233-6

39. Devotta A, Beno T, Siriki R, Löf R, Eynian M (2017) Finite element modeling and validation of chip segmentation in machining of AISI 1045 steel. Procedia CIRP 58:499-504. https://doi.org/ 10.1016/j.procir.2017.03.259

40. Thamizhmanii S, Sulaiman H (2012) Machinability study using chip thickness ratio on difficult to cut metals by CBN cutting tool. Key Eng Mater 504-506:1317-1322

41. Astakhov VP, Xiao X, Lansing E (2008) A methodology for practical cutting force evaluation based on the energy spent in the cutting system. Mach Sci Technol An Int J 12:325-347. https:// doi.org/10.1080/10910340802306017
42. Arsecularatne JA (1997) On tool-chip interface stress distributions, ploughing force and size effect in machining. Int J Mach Tools Manuf 37:885-899. https://doi.org/10.1016/S08906955(97)00001-1

43 Joshi S, Tewari A, Joshi SS (2015) Microstructural characterization of chip segmentation under different machining environments in orthogonal machining of Ti6Al4V. J Eng Mater Technol Trans ASME 137:1. https://doi.org/10.1115/1.4028841

44. Pawade RS, Joshi SS (2011) Mechanism of chip formation in high-speed turning of inconel 718. Mach Sci Technol 15:132-152. https://doi.org/10.1080/10910344.2011.557974

45. Schulz H, Abele E, Sahm A (2001) Material aspects of chip formation in HSC machining. CIRP Ann - Manuf Technol 50:45-48. https://doi.org/10.1016/S0007-8506(07)62067-8

46. Kistler. Kistler Product Catalogue: sensors and solutions for cutting force measurement 2018. https://www.kistler.com/fileadmin/ files/divisions/sensor-technology/cutting-force/960-002e-05.14. pdf (accessed September 13, 2018).

Publisher's Note Springer Nature remains neutral with regard to jurisdictional claims in published maps and institutional affiliations. 